\title{
The Airborne Multiangle SpectroPolarimetric Imager (AirMSPI): a new tool for aerosol and cloud remote sensing
}

\author{
D. J. Diner ${ }^{1}$, F. Xu ${ }^{1,2}$, M. J. Garay ${ }^{1}$, J. V. Martonchik ${ }^{1}$, B. E. Rheingans ${ }^{1}$, S. Geier ${ }^{1}$, A. Davis ${ }^{3}$, B. R. Hancock ${ }^{1}$, \\ V. M. Jovanovic ${ }^{1}$, M. A. Bull ${ }^{1}$, K. Capraro ${ }^{1}$, R. A. Chipman ${ }^{4}$, and S. C. McClain ${ }^{4}$ \\ ${ }^{1}$ Jet Propulsion Laboratory, California Institute of Technology, Pasadena, CA 91109, USA \\ ${ }^{2}$ University of California, Los Angeles, CA 90095, USA \\ ${ }^{3}$ University of Texas, Center for Space Research, Austin, TX 78759, USA \\ ${ }^{4}$ University of Arizona, College of Optical Sciences, Tucson, AZ 85721, USA
}

Correspondence to: D. J. Diner (david.j.diner@jpl.nasa.gov)

Received: 9 January 2013 - Published in Atmos. Meas. Tech. Discuss.: 14 February 2013

Revised: 3 July 2013 - Accepted: 4 July 2013 - Published: 13 August 2013

\begin{abstract}
The Airborne Multiangle SpectroPolarimetric Imager (AirMSPI) is an eight-band (355, 380, 445, 470, 555, $660,865,935 \mathrm{~nm})$ pushbroom camera, measuring polarization in the 470, 660, and $865 \mathrm{~nm}$ bands, mounted on a gimbal to acquire multiangular observations over $\mathrm{a} \pm 67^{\circ}$ along-track range. The instrument has been flying aboard the NASA ER2 high altitude aircraft since October 2010. AirMSPI employs a photoelastic modulator-based polarimetric imaging technique to enable accurate measurements of the degree and angle of linear polarization in addition to spectral intensity. A description of the AirMSPI instrument and ground data processing approach is presented. Example images of clear, hazy, and cloudy scenes over the Pacific Ocean and California land targets obtained during flights between 2010 and 2012 are shown, and quantitative interpretations of the data using vector radiative transfer theory and scene models are provided to highlight the instrument's capabilities for determining aerosol and cloud microphysical properties and cloud 3-D spatial distributions. Sensitivity to parameters such as aerosol particle size distribution, ocean surface wind speed and direction, cloud-top and cloud-base height, and cloud droplet size is discussed. AirMSPI represents a major step toward realization of the type of imaging polarimeter envisioned to fly on NASA's Aerosol-Cloud-Ecosystem (ACE) mission in the next decade.
\end{abstract}

\section{Introduction}

Sunlight, the fundamental source of energy that drives our climate system, is modulated by spatially and temporally heterogeneous airborne particulate distributions. Aerosols affect Earth's energy and water cycles through direct radiative forcing, the magnitude and sign of which depends on a complex interplay of aerosol optical properties (optical depth, single scattering albedo, refractive index), shape and size distribution, and the albedo of the underlying surface (CCSP, 2009). Aerosols also influence cloud properties and precipitation (Lohmann and Feichter, 2005). Due to the high albedo and prevalence of clouds, small changes in cloud cover can have major climate impacts. The physical complexity of the processes associated with cloud formation, growth, and dissipation make cloud feedbacks the largest source of uncertainty in our ability to accurately predict climate sensitivity to increased greenhouse gas concentrations (Randall et al., 2007).

To advance our understanding of the climate and environmental impacts of different types of aerosols and the interactions between aerosols and clouds, the US National Research Council (NRC) recommends a future AerosolCloud-Ecosystem (ACE) mission (NRC, 2007) with a highaccuracy, wide-swath, multiangle polarimetric imaging instrument as part of the core payload. We are developing the Multiangle SpectroPolarimetric Imager (MSPI) as a candidate for ACE (Diner et al., 2007, 2010; Mahler et al., 2011a). Like its predecessor, the Multiangle Imaging SpectroRadiometer (MISR) currently flying on NASA's 
Terra spacecraft (Diner et al., 1998a), MSPI is envisioned to observe Earth at multiple view angles using a set of multispectral pushbroom cameras. Relative to MISR, new capabilities in MSPI will include ultraviolet and shortwave infrared bands in addition to those in the visible and near-infrared, a wider field of view (hence more frequent global coverage), and polarimetric imaging in selected spectral bands (MISR, by design, is polarization insensitive).

Development of the MSPI instrument has proceeded via construction of a series of prototype cameras with progressively increasing spectral capability. The initial prototype, designated LabMSPI, was a single wavelength $(660 \mathrm{~nm})$ camera designed to demonstrate our dual photoelastic modulator (PEM)-based polarimetric imaging approach. Example images and calibration results are presented in Diner et al. (2010). LabMSPI has since been upgraded to ultraviolet (UV)/visible/near-infrared (VNIR) operation and renamed GroundMSPI to distinguish it from its predecessor (Diner et al., 2012). A second, airborne version of the camera - AirMSPI, also operating in the UV/VNIR - has been flying on NASA's ER-2 high-altitude aircraft since 2010. Section 2 of this paper describes the AirMSPI instrument. Section 3 presents examples of intensity and polarization images, along with model results aimed at interpreting the observations. Concluding remarks are provided in Sect. 4.

\section{AirMSPI instrument description}

\subsection{Optics}

AirMSPI is an eight-band pushbroom camera, mounted on a gimbal to acquire multiangular observations over a $\pm 67^{\circ}$ along-track range. As in GroundMSPI, the AirMSPI spectral bands are centered near 355, 380, 445, 470P, 555, 660P, $865 \mathrm{P}$, and $935 \mathrm{~nm}$. Those bands marked with the letter "P" provide polarimetric information. The $935 \mathrm{~nm}$ channel is an experimental band included to explore the possibility of retrieving column water vapor abundance using multiangle observations. AirMSPI's telescope has an effective focal length of $29 \mathrm{~mm}$ and cross-track field of view of $\pm 15^{\circ}$. Incoming light is brought to a focus using a three-mirror f/5.6 anastigmatic, telecentric system of the same design as used in LabMSPI/GroundMSPI (Diner et al., 2010). To increase optical throughput, particularly in the UV, AirMSPI employs redesigned mirror coatings. In addition to high reflectance, design goals for the coatings included low diattenuation and low retardance (relative difference in reflectance and phase, respectively, for light polarized in perpendicular planes). Precision Asphere, Inc. fabricated the mirrors and Surface Optics Corporation applied the optical coatings. Over the entire UV-shortwave infrared (SWIR) spectral range, the measured diattenuation is $<0.5 \%$, reflectance is $>85 \%$, and retardance is $<10^{\circ}$. Because diattenuation is intrinsically low for the new coating design, the diattenuation balancing approach used in GroundMSPI (Mahler et al., 2008) was not required and each mirror was identically coated.

\subsection{Retardance modulator}

AirMSPI uses a time-varying retardance in the optical path to modulate the orientation of the linearly polarized component of the incoming light, described by the Stokes components $Q$ (excess of horizontally over vertically polarized light) and $U$ (excess of $45^{\circ}$ over $135^{\circ}$ polarized light) (Diner et al., 2007, 2010; Mahler et al., 2011a). This oscillating retardance is achieved by placing a pair of Hinds Instruments Series II/FS42 PEMs in the optical train. PEMs are fused silica plates coupled to quartz piezoelectric transducers that induce a rapidly oscillating retardance via the photoelastic effect. The fast axes of the two PEMs are aligned and nominally parallel to the long dimension of the focal plane line arrays. The AirMSPI PEMs have resonant frequencies of $f_{1}=42060$ and $f_{2}=42037 \mathrm{~Hz}$ at $18^{\circ} \mathrm{C}$. These frequencies shift by about $2.6 \mathrm{~Hz}$ per $1^{\circ} \mathrm{C}$ change in temperature, but the difference frequency $\delta f=f_{1}-f_{2}(23 \mathrm{~Hz})$ is much less temperature sensitive, changing by only $15 \mathrm{mHz}^{\circ} \mathrm{C}^{-1}$. The difference in resonant frequency of the two PEMs generates a beat signal whose period defines the duration of an image frame ( $t_{\text {frame }}=1 / \delta f=43.5 \mathrm{~ms}$ ). This beat modulation is typically sampled 23 times per frame, and the time-varying signal is processed using the algorithm described in Diner et al. (2010) to retrieve $I$ and $Q$ simultaneously from those pixels overlain by an analyzer that transmits light polarized in an orientation parallel to the line arrays, and $I$ and $U$ from those pixels overlain by a polarization analyzer oriented at $45^{\circ}$ to this direction. $I$ is the first Stokes component (intensity). By virtue of this approach, the ratios $q=Q / I$ and $u=U / I$ are, to first order, insensitive to the absolute radiometric calibration of a given pixel because both the numerator and denominator are determined from signals acquired by the same detector element. The degree of linear polarization (DOLP) and angle of linear polarization (AOLP) derived from these ratios, equal to $\sqrt{q^{2}+u^{2}}$ and $0.5 \tan ^{-1}(u / q)$, respectively, are similarly insensitive to absolute calibration. To compensate for instrumental polarization aberrations (e.g., mirror diattenuation, imperfect retardance), a set of 10 polarimetric calibration coefficients is established for every pixel (Diner et al., 2010). These features enable the MSPI class of instruments to meet the ACE DOLP uncertainty requirement of \pm 0.005 (ACE Science Working Group, 2010). Results from LabMSPI (Diner et al., 2010) and GroundMSPI (Diner et al., 2012) show DOLP uncertainties, determined as the root-mean-square (RMS) residual in DOLP as a polarizer is rotated in stepwise fashion in front of the camera (see Diner et al., 2010, for a description of the methodology), of \pm 0.003 or better. Preliminary results for AirMSPI show similar residuals.

Quarter-wave plates (QWPs) located in the optical path before and after the PEMs result in modulation of the two 
desired linear Stokes vector components, $Q$ and $U$. Without the QWPs, the camera would be sensitive to $U$ and $V$, the latter being the excess of right-handed over left-handed circular polarization. Since $V$ is typically small for natural scenes (Plass et al., 1976; Kawata, 1978), measurement of this Stokes component is sacrificed in order to obtain sensitivity to both $Q$ and $U$. In the single-band LabMSPI camera, zero-order quartz QWPs were used. For GroundMSPI, these were replaced with commercial QWPs constructed from quartz and magnesium fluoride $\left(\mathrm{MgF}_{2}\right)$. Custom QWPs were designed and fabricated to meet the more stringent AirMSPI performance requirements (Mahler et al., 2011b). The design goal was to achieve retardance within $\pm 10^{\circ}$ of $90^{\circ}$ (one quarter wave) in the polarimetric bands and $<0.1^{\circ}$ retardance change with $1^{\circ} \mathrm{C}$ change in temperature. The use of a composite, three-element retarder provides three degrees of freedom, two of which were designated for the shape of the retardance curve and the third for athermalization. The three materials employed are quartz, $\mathrm{MgF}_{2}$, and sapphire. Karl Lambrecht Corporation assembled the AirMSPI compound retarders. Nominal retardance is 90,92 , and $86^{\circ}$, respectively, at 470,660 , and $865 \mathrm{~nm}$. Deviations of QWP performance from exact quarter-wave and the effect of finite spectral bandwidth are accounted for in the coefficients derived as part of the polarimetric calibration process (Diner et al., 2010).

\subsection{Focal plane spectropolarimetric filters}

A miniaturized focal-plane assembly consisting of spectral filters and wire-grid polarizers (WGPs) provides wavelength and polarimetric discrimination. Intensity measurements in the near-UV are beneficial because most surfaces are dark at these wavelengths, and the interaction between aerosols and enhanced Rayleigh scattering provides sensitivity to aerosol height (e.g., Torres et al., 2002). Visible and near-infrared intensity and polarization measurements provide sensitivity to particle size and complex refractive index. The longestwavelength channel of AirMSPI is located in a water vapor absorption band. The nominal band center wavelengths and bandpass specifications (shown in parentheses) provided to the filter manufacturer were $355(30), 380(32), 445(36)$, 470(37), 555(31), 660(42), 865(39), and 935(48) nm. To enable spectral and polarimetric selection for different rows of the photodetector line arrays, the manufactured spectral filters were sliced into thin strips $(80 \mu \mathrm{m}$ wide by $17 \mathrm{~mm}$ long), bonded together, and polished. Materion Barr Precision Optics designed and fabricated this "butcher block" assembly. Design and manufacture of the filters, slicing and bonding to a substrate, incorporation of WGPs into the polarimetric channels, and integration of the resulting filter assembly with the camera optics and detectors can cause the systemlevel spectral characteristics of the AirMSPI channels to differ slightly from the specified values. This paper references and analyzes data from each channel using the nominal (i.e., specified) band-center wavelengths. System-level spectral characterization is underway, and details will be summarized in a separate publication. Preliminary analyses of monochromator measurements of the as-built system indicate that the above specifications are met within a few $\mathrm{nm}$.

The butcher-block filter assembly makes use of high optical density black epoxy between the spectral filters for stray light reduction. This assembly was bonded to a fused silica substrate containing patterned WGPs in the polarization channels. Moxtek, Inc. supplied the WGPs. Application of a cement bond to the WGPs results in reduced transmittance $T$ and polarization extinction ratio $\varepsilon$ (ratio of transmittance of the polarization state aligned with polarizer to the transmittance for the orthogonal state) relative to their pre-bond values. The use of high-contrast WGP stock results in post-bond $T$ exceeding $75 \%$ and $\varepsilon$ values between 40 and 100, depending on channel. These parameters affect the magnitude of the modulation pattern from the PEMs. As discussed in Diner et al. (2010), the systematic reduction in magnitude of the modulation pattern due to imperfect $T$ and $\varepsilon$ is corrected by instrument polarimetric calibration, though with increased sensitivity to random noise. For the worst-case values of $T$ and $\varepsilon$ relevant to AirMSPI, the corresponding reduction in signalto-noise ratio (SNR) introduces a random error in DOLP of less than \pm 0.0009 . A Mueller Matrix Imaging Polarimeter (MMIP) at the University of Arizona was used for inspection and characterization of the spectropolarimetric filter components. Alignment and bonding of the filter to the silicon complementary metal oxide semiconductor (Si-CMOS) imager was done at the Jet Propulsion Laboratory (JPL). The composite filter assembly is situated above the detector array in the camera focal plane. The precision positioning equipment used to accomplish this step is able to ensure alignment to within $\pm 2 \mu \mathrm{m}$ over the $17 \mathrm{~mm}$ length of the filter.

\subsection{Focal plane detectors}

Both the GroundMSPI and AirMSPI instruments use the same Si-CMOS line array detectors. JPL designed the detectors and readout integrated circuits. These devices are sensitive to light in the UV/VNIR spectral range. Sixty-four lines on $16 \mu \mathrm{m}$ spacing contain 1536 pixels with $9.5 \mu \mathrm{m}$ (crosstrack) $\times 10 \mu \mathrm{m}$ (along-track) apertures. Tower Semiconductor, Ltd. fabricated the detector array. Top-level characteristics are shown in Table 1. Reset noise is minimized through the use of correlated double sampling (CDS), in which the values on all capacitors are digitized and read out at the start of each integration interval and temporarily stored off-chip and then subtracted from the integrated values as they are read out. All 1536 pixels in a given row are integrated in parallel. 


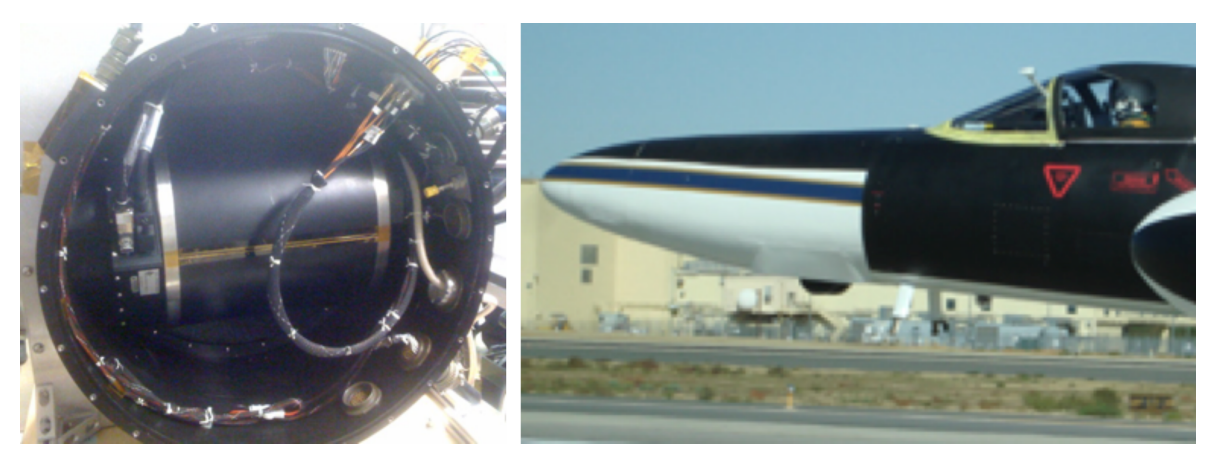

Fig. 1. Left panel: pressure vessel and cylindrical drum housing the AirMSPI camera. Right panel: AirMSPI installed in the nose of the ER-2. The instrument is visible protruding below the fuselage.

Table 1. Top-level characteristics of the AirMSPI focal plane detector.

\begin{tabular}{|c|c|}
\hline Parameter & Value \\
\hline Format & 1536 columns $\times 64$ rows \\
\hline Pixel sizes & $\begin{array}{l}9.5 \mu \mathrm{m}(\text { cross-track }) \times 10 \mu \mathrm{m} \\
\text { (along-track) }\end{array}$ \\
\hline Pixel spacing & $\begin{array}{l}10 \mu \mathrm{m}(\text { cross-track) } \times 16 \mu \mathrm{m} \\
\text { (along-track) }\end{array}$ \\
\hline Dark current & $0.5 \mathrm{e}^{-} \mathrm{s}^{-1}$ \\
\hline Conversion gain & $\sim 25 \mu \mathrm{V} / \mathrm{e}^{-}$peak \\
\hline Quantum efficiency at $660 \mathrm{~nm}$ & $35 \%$ \\
\hline Full well & $80000 \mathrm{e}^{-}$ \\
\hline Noise floor & $9 \mathrm{e}^{-}$ \\
\hline Readout rate & $>25 \mathrm{Mpix} \mathrm{s}^{-1}$ \\
\hline Power & $90 \mathrm{~mW}$ \\
\hline Polarization sensitivity & $<1 \%$ \\
\hline
\end{tabular}

\subsection{Electronics}

AirMSPI electronic circuits were designed and built to meet the dual-PEM polarimeter signal timing and phasing requirements outlined in Diner et al. (2007). Polarimetric accuracy is maximized by properly sampling the video signal and by synchronizing the sampling with the retardance modulation of the dual PEM. Each of the two AirMSPI PEM controllers drives an all-digital phase locked loop (PLL). This enables the phase of each PEM to be available at all times. Synchronization to the high frequency modulation and low beat frequency is accomplished by computing the sum and difference of the two PEM phases. In GroundMSPI, the support electronics are divided between a focal plane array (FPA) board and a data recovery board (DRB) (Diner et al., 2012). For AirMSPI, these circuits were combined into a single focal plane control and processing (FPCP) board that makes use of a Xilinx military-grade Virtex-5FXT field programmable gate array (FPGA) in place of the Spartan-3 used in GroundMSPI. Wide dynamic range is made possible by the large detector full well and 9 bit nonlinear quantization during each image frame. Digital encoding is linear at very low signal levels, and follows a square root law for most of the dynamic range. This is designed to keep quantization noise below $50 \%$ of the shot noise level. Finer quantization would not improve system SNR significantly because shot noise is the dominant source of measurement uncertainty.

\subsection{Instrument housing}

The AirMSPI housing reuses much of the hardware developed for its nonpolarimetric precursor, AirMISR (Diner et al., 1998b). The camera is mounted on a gimbal to permit multiangle imaging. Like AirMISR, the housing containing the AirMSPI gimbal assembly is mounted in the nose of the NASA high-altitude ER-2 aircraft. As shown in Fig. 1, the aluminum cylinder assembly protrudes below the aircraft fuselage. A pressure box around the gimbal assembly maintains $276 \mathrm{hPa}(4 \mathrm{psi})$ pressure inside the nose compartment, and the sensor head experiences outside ambient pressure ( $\sim 48 \mathrm{hPa}$ or $0.7 \mathrm{psi}$ at $20 \mathrm{~km}$ altitude). The camera and rotary stage cabling is led out through a set of pressure bulkhead connectors to the instrument electronics rack. The ER-2 supplies 28 VDC power to the instrument. The instrument draws $\sim 181 \mathrm{~W}$ of power during data acquisition, with an additional $70 \mathrm{~W}$ worth of independent heaters distributed through the camera volume to ensure that the instrument temperature does not drop below the dew point during aircraft descent. Re-engineering of the electronics and data system layout reduced instrument mass from $\sim 170 \mathrm{~kg}$ for AirMISR to $86 \mathrm{~kg}$ for AirMSPI.

\subsection{Gimbal drive}

In transitioning from AirMISR to AirMSPI, the gimbal and motor drive were upgraded to a system (Aerotech WaferMax T-RE2048AS) having much higher torque and a precision angle encoder, enabling more flexible operating and camera pointing modes (AirMISR acquired imagery at only 
a predefined set of nine view angles). The gimbal enables image acquisition at a programmable set of along-track angles between $\pm 67^{\circ}$. While it is possible to acquire observations at larger view angles, aircraft attitude fluctuations significantly degrade the quality of the imagery. Sequences to be used during a given flight are pre-programmed on the ground, and are constructed from two basic operating modes, illustrated in Fig. 2. In "step and stare" mode, the camera is pointed at the same target area at a fixed set of view angles beginning with the most forward view and then stepping aftward as the aircraft flies downtrack. The camera then slews forward and the sequence repeats for the next target, about $100 \mathrm{~km}$ downtrack. This mode is most useful where the highest possible spatial resolution $(\sim 10 \mathrm{~m})$ is desired. Target area is $\sim 10.6 \mathrm{~km}$ cross-track (at nadir) $\times 9.5 \mathrm{~km}$ along-track for a nominal sequence containing nine view angles. An odd number of "stares" is typically selected so that the images are acquired for a set of symmetric view angles forward and aftward of the nadir $\left(0^{\circ}\right)$ view angle. The along-track sample spacing ( $8 \mathrm{~m}$ at any angle) is set by the frame time and aircraft speed. In "continuous sweep" mode, the gimbal slews back and forth. Because the gimbal moves continuously, spatial resolution is reduced to $\sim 50 \mathrm{~m}$ due to smear. However, this mode enables better spatial coverage of multilayered cloud fields. AirMSPI's actuator permits the slew rate to vary as a continuous function of angle in order to keep the amount of image smear constant at all angles.

A variant of the first operating mode, dubbed "step and pseudostare", is made possible by the programmable nature of the AirMSPI actuator. During each of the "stare" portions of the sequence, the gimbal drifts forward at a slow rate (between a few hundredths and a few tenths of a degree per second, depending on view angle), enabling extension of the along-track length of the observed target areas. For example, without the drift, overlap imagery of nine multiangle views can be obtained with a $9.5 \mathrm{~km}$ target length, as noted above. Allowing a small amount of forward drift in the view angle during image acquisition introduces only $2 \mathrm{~m}$ of alongtrack smear and extends the target length to $11.5 \mathrm{~km}$. This mode has been successfully tested in flight. Acquisition of step and pseudostare imagery at up to 31 view angles has been demonstrated.

\subsection{On-board polarization monitoring and control systems}

Two specialized pieces of equipment for verifying and controlling the performance of the polarimetric measurement approach during in-flight operations of AirMSPI were developed and implemented. The first is a simple polarization "validator." As described above, the temperature sensitivity of QWP retardance has been minimized by design, though it is still possible that the retardance may shift somewhat due to temperature changes during flight. Illumination of the camera with light polarized at $0,15,60$, and $75^{\circ}$ provides a useful

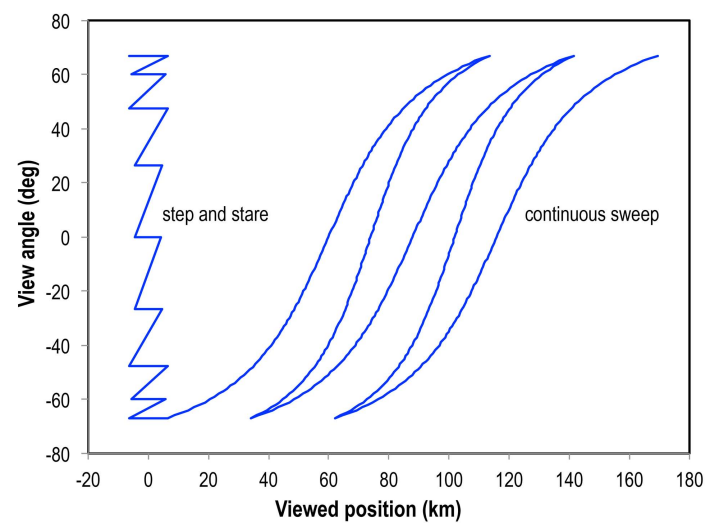

Fig. 2. Example of the AirMSPI "step and stare" mode, with nine view angles, showing view zenith angle at the center of the camera field of view as a function of viewed downtrack position on the ground, and the "continuous sweep" mode, in which the gimbal slews back and forth providing variable view angles and wider areal coverage than is possible in step and stare mode.

means for determining the deviations of the polarization calibration coefficients from their nominal values as a result of QWP retardance shifts. A source of light linearly polarized in these different orientations was designed and constructed for the AirMSPI camera to view in flight. This source consists of nine light-emitting diodes (LEDs), three each at the AirMSPI polarimetric wavelengths. These illuminate a plastic diffuser. In front of this source, sheet polarizers at the required orientations were installed, and this assembly was integrated into the AirMSPI instrument. The validator is not designed for absolute polarimetric calibration, but rather to provide a sufficiently polarized input to the AirMSPI camera such that the shape of the modulation waveform can be used to derive the average PEM retardance. The degree of linear polarization of the validator varies across the camera field of view, and has average values of $0.79,0.88$, and 0.16 at 470,660 , and $865 \mathrm{~nm}$, respectively. The validator is viewed by rotating the gimbal forward to an angle of $87^{\circ}$. The LEDs flash for $1 \mathrm{~s}$ every $10 \mathrm{~s}$ so that dark data can be collected between the illumination flashes. Validator data have been used to evaluate the in-flight PEM retardance and phase control system, known as the "optical probe."

The optical probe sends a beam of light through the PEMs to monitor their retardances and phases. The beam traverses the PEMs in an area not used for acquisition of Earth imagery. The light source in the optical probe is a $760 \mathrm{~nm}$ LED, and a combination of two linear polarizers and a QWP generates the required optical signals. The digitized output is synchronously demodulated and the system generates error signals showing how far the PEM retardances and phases are from their desired values. Four quantities are determined: the mean retardance of the two PEMs, the difference in retardance between the two PEMs, the phase of the low-frequency beat pattern, and the phase of the high-frequency oscillation. 
The feedback control system then adjusts the PEM parameters to drive the error signals to zero. The same Virtex-5FXT FPGA that operates the rest of the AirMSPI camera performs probe data acquisition and processing. During an AirMSPI flight on 31 August 2011, the probe was operated open loop (i.e., the PEMs were monitored but not controlled). Subsequently, a feedback algorithm was implemented to enable closed-loop operation, which was first used during a flight on 6 January 2012. Analysis of imagery of the light flashes from the onboard validator hardware enabled an independent measure of PEM retardance. The resulting data demonstrated the ability to control the PEM retardance and phase parameters to within a fraction of $1 \mathrm{mrad}$, keeping contributions to the overall DOLP uncertainty budget at $<0.001$.

\subsection{Data acquisition and ground processing}

Flight control software consists of data acquisition routines, gimbal operation instructions, and a main program. A Condor CEI-200 two-channel ARINC-429 board in the AirMSPI on-board computer receives ER-2 attitude and position data. The original AirMISR on-board data system was upgraded by replacing the hard disks with solid state memory and adding a CameraLink data collection system. An IO Industries frame grabber and disk shuttle packs are used. The current $4 \times 256$ GB Serial Advanced Technology Attachment (SATA) solid-state drives (SSDs) provide $\sim 1$ TB of memory, enabling storage of $\sim 10 \mathrm{~h}$ of data. The SSDs are exchangeable after a flight within minutes, allowing the instrument to be immediately flight-ready for a follow-up mission.

Accurate position and attitude data are required for georectification and co-registration of the different channels of AirMSPI data. The camera acquires image data in pushbroom fashion (one image line at a time for each channel). Image lines (frames) are acquired at a rate of $23 \mathrm{~Hz}$. To georectify and co-register the acquired imagery with subpixel accuracy, aircraft position and attitude data are used to define the viewing geometry of each image line. AirMSPI's ARINC-429 board receives attitude and position data at $64 \mathrm{~Hz}$ from the ER-2's inertial navigation/global positioning system (INS/GPS) to meet ground data processing requirements for image navigation (Jovanovic et al., 2001, 2012).

Data product generation makes use of the AirMSPI Data Processing System (AMDPS), which employs software developed for AirMISR (Jovanovic et al., 2001) and MISR (Jovanovic et al., 2002). Level 1A1 processing reformats the raw AirMSPI output into hierarchical data format (HDF). Level $1 \mathrm{~A} 2$ performs data conditioning, such as compensation for detector nonlinearity and dark level subtraction. Level 1B1 extracts the Stokes parameters $I, Q$, and $U$ and their linear gradients during each image frame, and applies pixel-by-pixel radiometric gain coefficients. Level 1B2 spatially co-registers the channels, maps the observations to the surface terrain, corrects for residual instrument polarization, and derives DOLP and AOLP relative to both the view meridian plane (the plane containing the view vector and the surface normal) and the scattering plane (the plane containing the view vector and the solar illumination vector).

\section{AirMSPI flight imagery}

\subsection{Data product examples}

The maiden flight of AirMSPI took place on 7 October 2010 and demonstrated successful operation of the dual-PEM polarimetric imaging technology in the high-altitude airborne flight environment (Diner et al., 2011). Figure 3 shows examples of georectified nadir imagery of the area near Palmdale, CA, acquired during this flight. Compared with the natural color image (upper left), the lower surface contrast and bluish hue in the image generated from the shortest wavelength bands (upper right) result from the increase in atmospheric path radiance in the blue and UV. In the latter image, the discolored, darker stripes are parallel to the flight direction and are due to imperfections in the spectral filters, leading to inaccurate radiometric calibration. A correction algorithm is currently under development. The lower left image shows intensity at 470, 660, and $865 \mathrm{~nm}$. Vegetated areas appear red due to the high reflectance of leaves in the NIR. The lower right image is DOLP at 470,660 , and $865 \mathrm{~nm}$. The highly polarized square features in the lower left portion of the image are wastewater treatment ponds at the Palmdale Water Reclamation Plant.

Figures 4 and 5 demonstrate the effectiveness of the AirMSPI georectification process. Figure 4 is a Level 1B1 $660 \mathrm{~nm}$ intensity image acquired on 6 January 2012 over Fresno, CA, at a view angle of $67^{\circ}$. Distortions due to aircraft attitude fluctuations are apparent in the image. Imagery at this oblique angle is most sensitive to variations in aircraft pitch. The georectified and map projected (Level 1B2) image is shown in Fig. 5. Automated data processing makes use of aircraft navigation information to correct for image distortions. In general, the navigation information is used in conjunction with any available ground control and multi-image tie points to establish and account for absolute orientation of the camera to the platform frame of reference and potential time dependent drift (Jovanovic et al., 2001, 2012).

Figure 6 shows examples of the AirMSPI image products generated by the AMDPS. The data shown are from a flight over the ports of Los Angeles and Long Beach on 26 October 2010 . The wavelength is $865 \mathrm{~nm}$ and the view angle is $24.6^{\circ}$ aftward of nadir as the ER-2 was flying on a heading of $\sim 11^{\circ}$ east of north. Solar zenith and azimuth angles were 46.8 and $350.3^{\circ}$, respectively (azimuth angles are defined as the direction of photon travel relative to local north). The data have been map-projected to a $10 \mathrm{~m}$ grid, and the area shown measures $8.7 \mathrm{~km} \times 5.7 \mathrm{~km}$. Each of the images was individually contrast enhanced to highlight detail, except that $Q$ and $U$ had an identical stretch applied to preserve their relative 


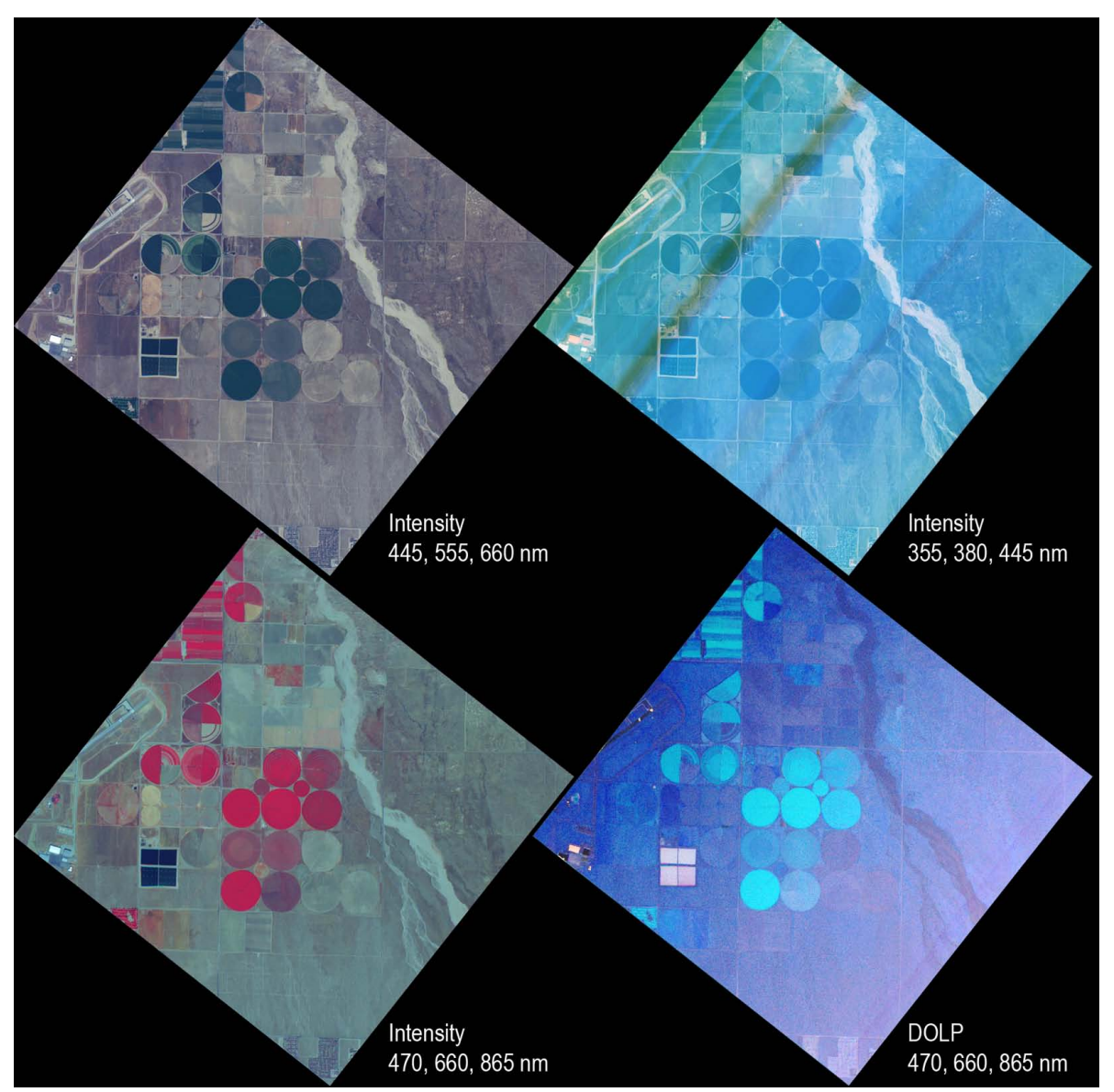

Fig. 3. Georectified imagery acquired during AirMSPI's maiden flight on 7 October 2010. Top left panel: intensity at 445, 555, and 660 nm displayed as blue, green, and red. Top right panel: intensity at 355, 380, and $445 \mathrm{~nm}$ displayed as blue, green, and red. Bottom left panel: intensity at 470, 660, and $865 \mathrm{~nm}$ displayed as blue, green, and red. Bottom right panel: DOLP in the same spectral bands. Flight direction is from upper right to lower left. The darker, discolored stripes in the top right image are due to defects in the spectral filters. Improved calibration of these pixels is under investigation.

magnitudes. In the intensity image, the water is somewhat darker than the land and exhibits a gradient toward the lower right portion of the image where specular reflection off the water (sunglint) becomes brighter. Boat wakes and surface waves are apparent in the water. Sunglint off the ocean surface results in high values of DOLP (up to $\sim 0.70$ ). AOLP with respect to the scattering plane takes on values close to $90^{\circ}$, as expected for a scene dominated by Fresnel surface reflection and single scattering. The " $Q, U$ " images are false color composites in which $Q$ and $U$ are displayed in shades of red and cyan, respectively. Two versions are shown, one in which $Q$ and $U$ are defined with respect to the view meridian plane, the other in which they are defined with respect to the scattering plane. In addition to $I, Q, U$ and the derived products DOLP and AOLP, the subframe sampling also enables determination of the linear gradient in intensity during the course of an image frame (Diner et al., 2010). This parameter is determined in both the polarimetric and nonpolarimetric channels, and can be used either as a textural measure or a means of enhancing the along-track spatial resolution of the imagery. The relative change in intensity $(\Delta I / I)$ is displayed as the upper right panel in Fig. 6.

\subsection{Clear sky observations over ocean}

Theoretical sensitivity studies (e.g., Hasekamp and Landgraf, 2007; Lebsock et al., 2007) show that polarization and intensity data provide complementary constraints on particle properties. The Decadal Survey (NRC, 2007) notes that "a combination of multiangle, multispectral, and polarization capabilities ... provides the greatest potential to monitor aerosols from space." Airborne Research Scanning Polarimeter (RSP) data (Cairns et al., 2003) show that multiangle (nonimaging) polarimetry distinguishes aerosols that otherwise appear similar in intensity, through improved sensitivity to effective particle radius, size variance, and refractive index (Chowdhary et al., 2001, 2002; Mishchenko and Travis, 1997) as well as water-leaving radiance (Chowdhary 


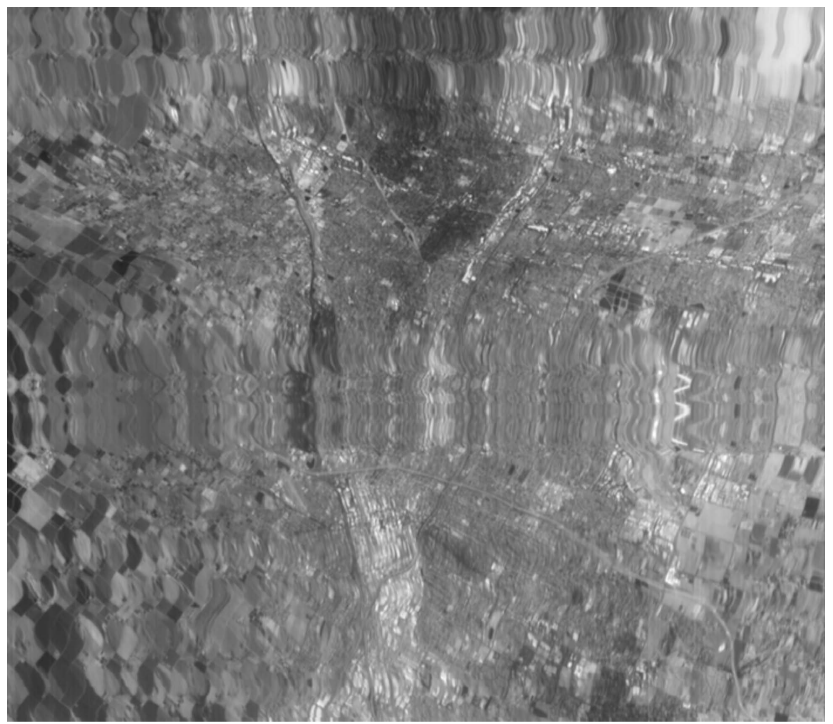

Fig. 4. Among the steps in AirMSPI ground data processing is generation of Level 1B1 calibrated imagery. Rapid aircraft attitude fluctuations give rise to distortions from line to line. This $660 \mathrm{~nm}$ intensity image over Fresno, CA, on 6 January 2012 was acquired at a view angle of $67^{\circ}$ and shows these distortions, which are particularly evident at the top and center of the image.

et al., 2012). Hasekamp et al. (2011) applied a coupled ocean-atmosphere algorithm to Polarization and Directionality of Earth's Reflectances (POLDER) satellite data to retrieve chlorophyll $a$ concentration, surface wind velocity, and fractional foam coverage, along with optical and microphysical parameters describing a bimodal aerosol model. The inclusion of polarization reduced both the bias and spread of aerosol optical depth (AOD) and Angstrom exponent (AE) retrievals relative to Aerosol Robotic Network (AERONET) data (Holben et al., 1998), with the most significant improvement occurring in $\mathrm{AE}$, most likely due to increased sensitivity to particle size. An intercomparison of satellite aerosol retrieval algorithms suggests that supplementing multiangle intensity observations with polarimetric measurements increases sensitivity to complex refractive index (Kokhanovsky et al., 2010).

A near-simultaneous overpass of a patch of clear sky over ocean by both MISR on the Terra satellite and AirMSPI on the ER-2 on 19 July 2012 supports many of these arguments. Figure 7 shows a MISR natural color, nadir image acquired at 11:58 PDT (18:58 UTC), within which is the area observed by AirMSPI (denoted by the yellow marker) at $32.4^{\circ} \mathrm{N}, 121.6^{\circ} \mathrm{W}$. The AirMSPI data were acquired as part of a 21-angle step-and-pseudostare sequence. The sequence took about $7.6 \mathrm{~min}$, and the nadir view shown in Fig. 8 was acquired about $28.5 \mathrm{~min}$ after the MISR overpass. The MISR standard V22 aerosol product (Kahn et al., 2010) reported low AOD; two of the 74 aerosol models in the MISR database that passed the goodness-of-fit metrics

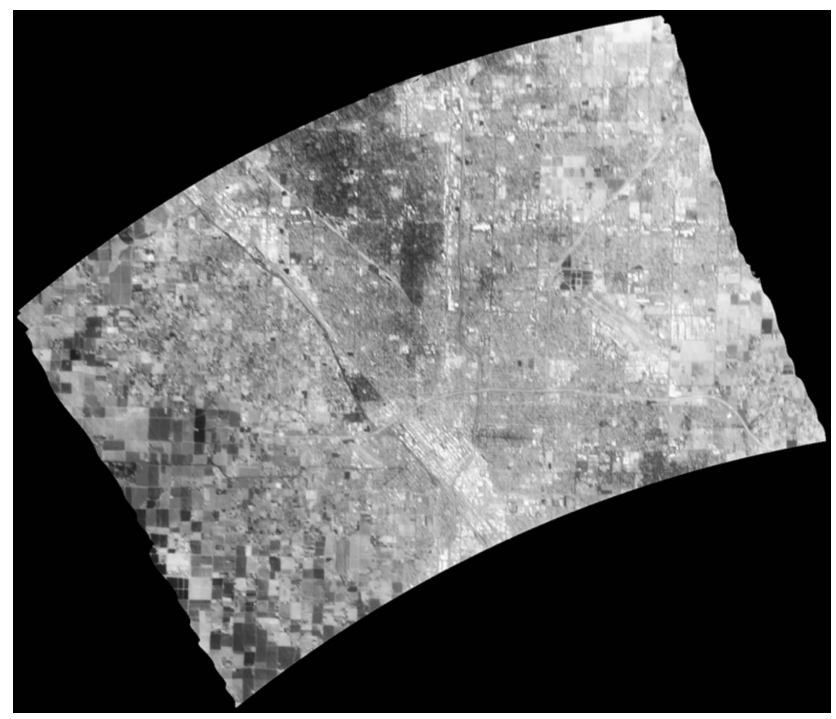

Fig. 5. Georectification and map projection at Level 1B2 makes use of high frequency navigation information to correct for distortions due to aircraft attitude fluctuations. Here, the data from Fig. 4 have been mapped to a Universal Transverse Mercator projection.

were Mixture 11, consisting of a single lognormal size distribution having median radius of $0.06 \mu \mathrm{m}$, standard deviation of lognormal radius distribution $=0.53$, effective radius $=0.12 \mu \mathrm{m}$, and Mixture 8, consisting of $40 \%$ (fractional AOD at $558 \mathrm{~nm}$ ) of a fine mode (median radius $=0.03 \mu \mathrm{m}$, standard deviation of lognormal radius distribution $=0.50$, effective radius $=0.06 \mu \mathrm{m}$ ) and $60 \%$ of a coarse mode (median radius $=1.00 \mu \mathrm{m}$, standard deviation of lognormal radius distribution $=0.64$, effective radius $=2.80 \mu \mathrm{m}$ ). All particles are nonabsorbing and have a spectrally invariant refractive index of 1.45 . The retrieved AODs at $558 \mathrm{~nm}$ for Mixtures 11 and 8 were 0.077 and 0.078 , respectively. The nearest AERONET site (green marker, $\sim 170 \mathrm{~km}$ away) is on the coast at the University of California, Santa Barbara (UCSB). At 12:21 PDT (19:21 UTC) the Level 1.5 AERONET AOD, interpolated to $558 \mathrm{~nm}$, is 0.077 (Level 2.0 AERONET data are currently not available for this site on this date).

AirMSPI data near the center of each multiangle image were averaged over a patch size of $\sim 100 \mathrm{~m} \times 100 \mathrm{~m}$. To provide a measure of variability within the patch, standard deviations of the observations were also computed. The absolute radiometric calibration of the AirMSPI imagery was based on preliminary gain coefficients derived from laboratory observations of the MISR $1.65 \mathrm{~m}$ integrating sphere (Bruegge et al., 1998) in 2011, using an Analytical Spectral Devices spectrometer as the reference standard. Significant time has passed since that calibration was performed. In addition, the radiant output of the sphere in the UV and short wavelength blue channels did not cover enough of the AirMSPI dynamic range to ensure accurate gain coefficient determination in these bands. Consequently, the MISR integrating sphere was 


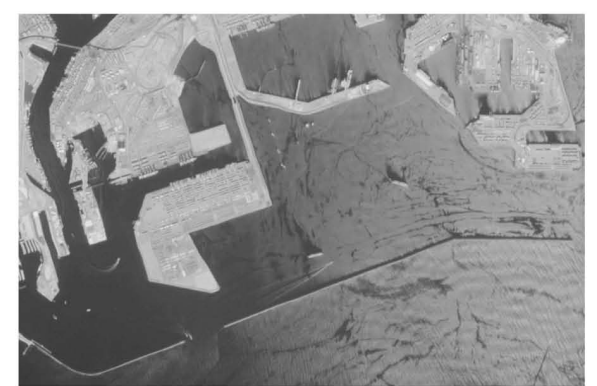

Intensity

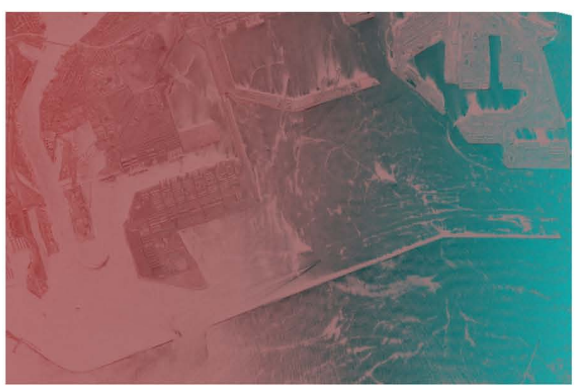

$\mathrm{Q}, \mathrm{U}$ (meridian plane)

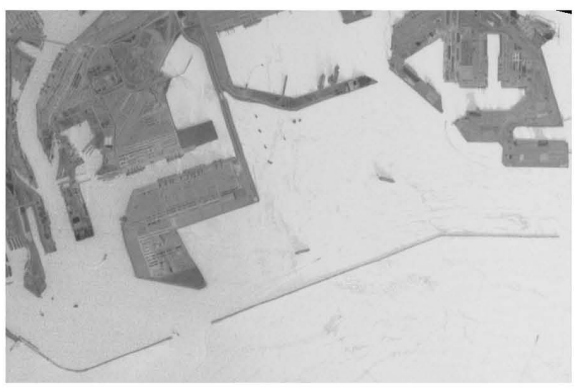

DOLP

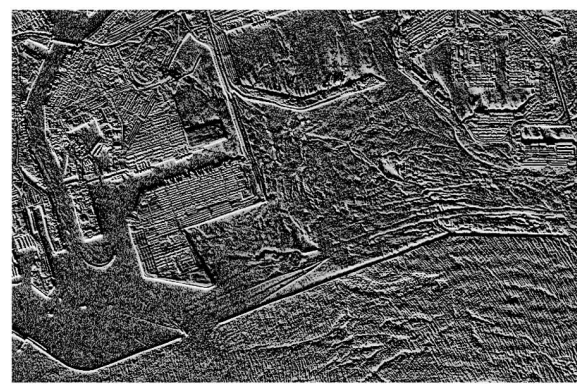

Relative intensity gradient

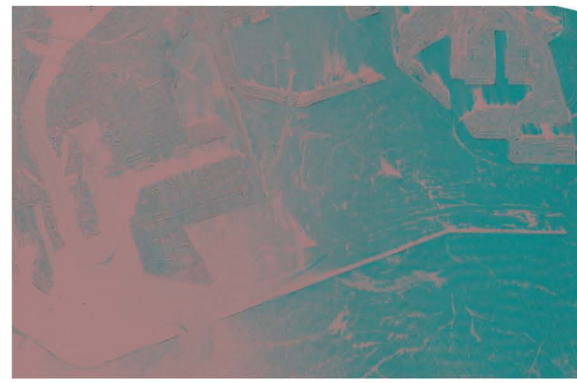

$\mathrm{Q}, \mathrm{U}$ (scattering plane)

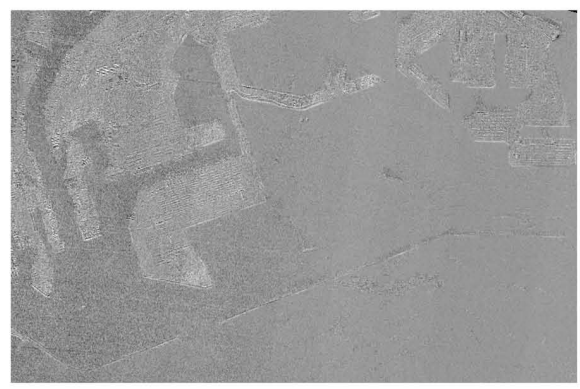

AOLP (scattering plane)

Fig. 6. Ports of Los Angeles/Long Beach data acquired 26 October 2010. Images are from the $26^{\circ}$ aftward view at $865 \mathrm{~nm}$. The area shown measures $8.7 \mathrm{~km} \times 5.7 \mathrm{~km}$. Spatial resolution is $10 \mathrm{~m}$. The " $Q, U$ " images are false color composites in which $Q$ and $U$ are displayed in shades of red and cyan, respectively. Two versions are shown, one defined with respect to the view meridian plane, the other defined with respect to the scattering plane. AOLP derived from the latter takes on values very close to $90^{\circ}$. Sunglint results in high values of DOLP over the water.

recently sent to the manufacturer (Labsphere, Inc.), recoated, and outfitted with Luxim light emitting plasma (LEP) lamps to improve light levels, particularly at the short wavelengths. In addition, measurements of the per-pixel spectral response functions are currently being performed using a monochromator, which will allow more accurate determination of the exo-atmospheric solar irradiance to be assigned to each channel. As these improved laboratory calibrations are not yet complete, the near-simultaneous, well-calibrated MISR observations were used to achieve a vicarious calibration of the AirMSPI flight data.

Under the assumption that ambient conditions varied little between the MISR and AirMSPI overpasses, the MISR Mixture 11 aerosol model was used to predict upwelling radiances in the AirMSPI spectral bands, taking into account the differences in view and illumination geometry between the two instruments and the $20 \mathrm{~km}$ flight altitude of the ER2. A vector Markov chain radiative transfer code (Xu et al., 2011) was used to perform the radiative transfer computations. Because this model does not currently account for absorption by water vapor, the $935 \mathrm{~nm}$ channel was not included in the analysis. Rayleigh scattering optical depth was based on the US standard atmosphere. Keeping the aerosol parameters supplied by MISR fixed, adjustments to the laboratory-derived radiometric gain corrections were determined along with wind speed and direction parameters of the anisotropic Cox-Munk model (Cox and Munk, 1956) to fit the multiangle, multispectral AirMSPI intensity and polarization data simultaneously. This ocean reflectance model assumes the surface to be comprised of an array of tilted 


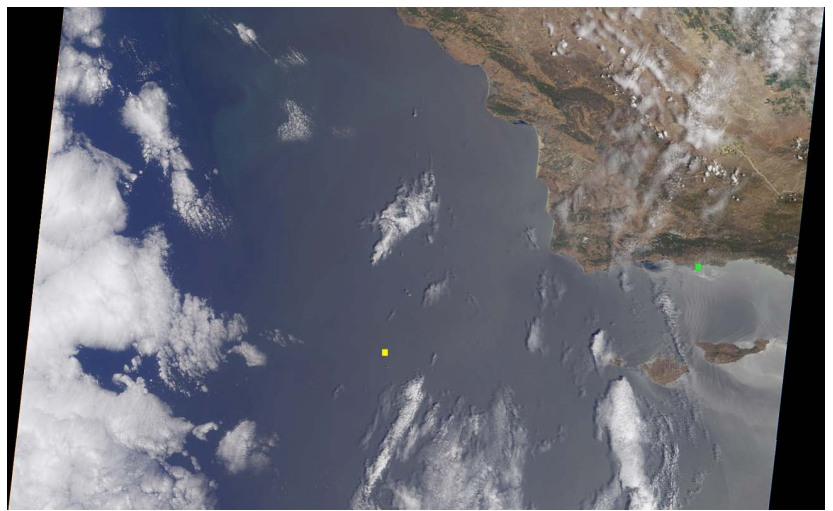

Fig. 7. MISR nadir image (Orbit 66950, Path 43) of an area off the coast of Southern California, acquired on 19 July 2012 at 11:58 PDT (18:58 UTC). The imaged area is about $380 \mathrm{~km}$ wide. The yellow marker below image center shows the location of an AirMSPI 21angle image sequence acquired shortly after the MISR overpass. The green marker on the coast near the right-hand edge of the image shows the location of the UCSB AERONET site.

microfacets reflecting according to Fresnel's equations and uses a generalized Gaussian slope distribution parameterized by the wind direction relative to the solar azimuthal plane and the RMS slope components in the upwind and crosswind directions, $\sigma_{\mathrm{u}}$ and $\sigma_{\mathrm{c}}$, respectively, which depend on wind speed. The model has been used successfully by Bréon and Henriot (2006) to retrieve wind speeds from POLDER sunglint data. To account for shadowing, the shadow function derived for an isotropic Gaussian facet distribution (Tsang et al., 1985 and references therein) is adopted here, with $\sigma^{2}$ replaced by $\sigma_{\mathrm{u}} \sigma_{\mathrm{c}}$. The spectral variation in water refractive index is included in the model. As the AirMSPI flight line was close to the principal plane, the anisotropic Cox-Munk model and variation in the sunglint magnitude with view angle enabled retrieval of the surface wind vector. Water-leaving radiance was taken to be zero at 660 and $865 \mathrm{~nm}$, and values in the blue and green were derived from MISR, assuming a Lambertian and depolarizing bidirectional reflectance distribution function. Although more sophisticated models of scattering by hydrosols are available (e.g., Chowdhary et al., 2006; Zhai et al., 2010), we opted for a simple model to capture the main features of the observations. The water-leaving bidirectional reflectance factors were linearly extrapolated into the UV, based on the relative trend with wavelength indicated by Koelemeijer et al. (2003). Correction for ozone absorption used a climatological value of 314 Dobson units, the same value used in the MISR aerosol retrievals, with the assumption that only $20 \%$ of the ozone column-integrated optical depth is situated below $20 \mathrm{~km}$. Because AirMSPI determines DOLP as a relative measurement independent of instrument radiometric gain, polarized intensities in the 470,660 , and $865 \mathrm{~nm}$ bands

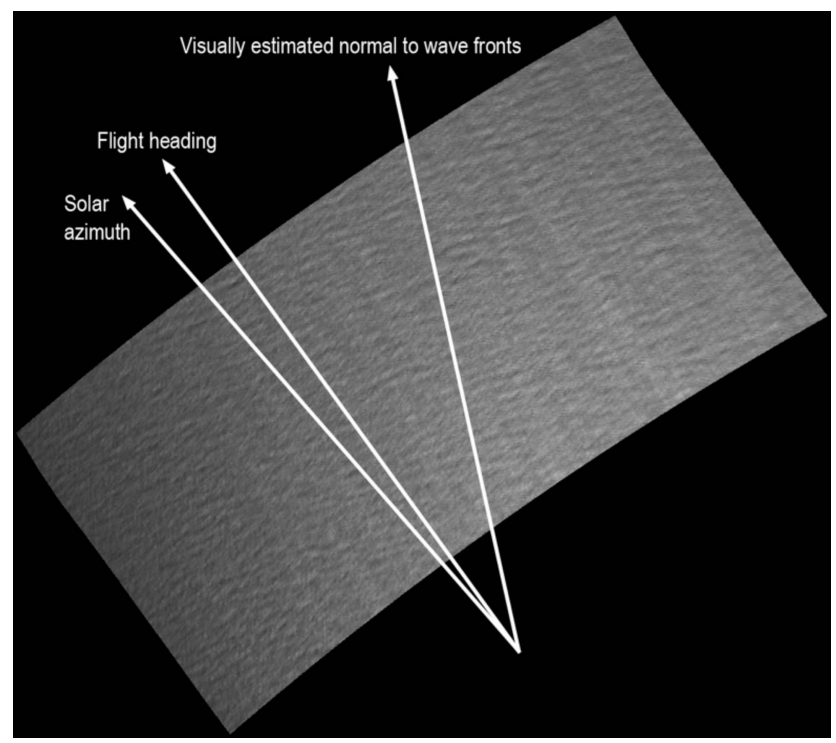

Fig. 8. AirMSPI nadir intensity image of the location marked in Fig. 7. This image was acquired $28.5 \mathrm{~min}$ after the MISR nadir image was acquired. The ER-2 with AirMSPI aboard was flying toward the northwest very close to the principal scattering plane, and a 21-angle image sequence was acquired. Here, sunglint illuminates the surface wave structure.

were calculated by taking the calibration-adjusted total intensities and multiplying by DOLP.

Comparisons between bidirectional reflectance factors (BRF) determined from the AirMSPI observations and the atmosphere-ocean model are shown in Fig. 9, comparisons between observed and modeled polarized BRF (pBRF) are shown in Fig. 10, and comparisons between observed and modeled DOLP are shown in Fig. 11. The RMS difference between measurement and model data over all angles and spectral bands is 0.004 in BRF and 0.002 in pBRF. Further improvements to the fit are likely possible by refining the aerosol model. For example, in Fig. 12 the MISR monomodal aerosol Mixture 11 is replaced with the bimodal Mixture 8, with all other scene parameters held constant. This figure shows that the bimodal model improves the agreement with observed DOLP at the oblique view zenith angles (RMS difference for view angles $>45^{\circ}$ improves from 0.036 to 0.024 ), and this mixture also provides a better agreement with the MISR observations based on the V22 goodness-of-fit metrics. However, the appearance of a bow resulting from the large particle component of Mixture 8 is inconsistent with the AirMSPI DOLP measurements, indicating that the assumed particle size of the coarse mode in the MISR lookup table is too large and/or the actual coarse component is dominated by nonspherical particles. Although aerosol type distinguishability in the current globally operational retrieval algorithm for MISR is reduced at low $(<0.15)$ AOD (Kahn et al., 2010), the AirMSPI data show that the addition of 


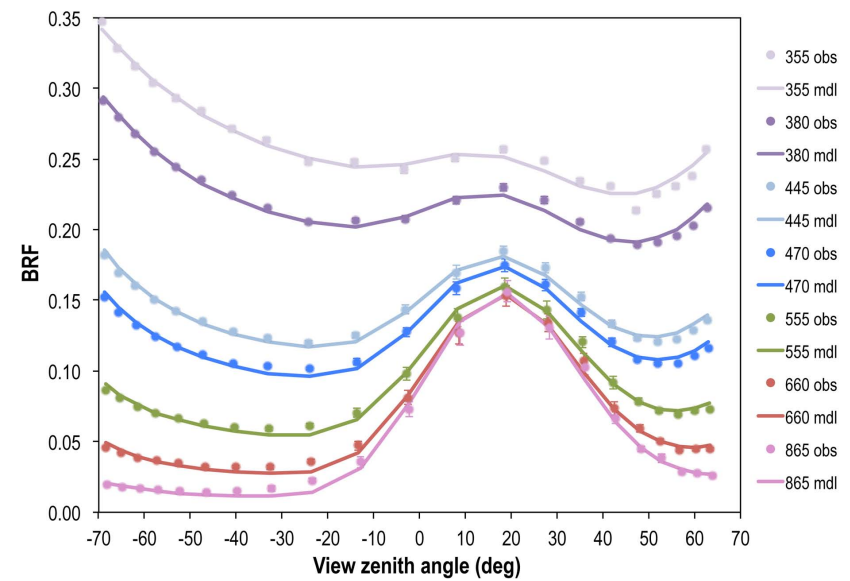

Fig. 9. Comparison of vicariously calibrated BRFs observed in seven AirMSPI bands with results of the coupled atmospheresurface model. Observations are shown by the circles. Error bars represent the standard deviation in observed BRF within the $100 \mathrm{~m} \times 100 \mathrm{~m}$ target area. Model results are the solid lines. Positively signed view zenith angles are those for which the relative view-Sun azimuth angle is $>90^{\circ}$ or $>270^{\circ}$; otherwise the view zenith angle is given a negative sign.

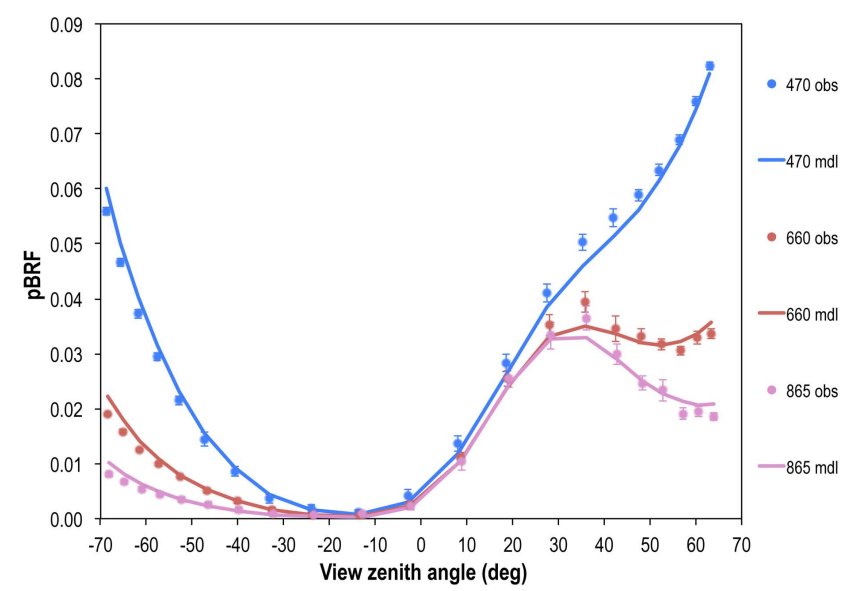

Fig. 10. Similar to Fig. 9 but for polarized BRFs in the three polarimetric AirMSPI bands.

polarimetric observations aids in constraining particle microphysical properties, even when aerosol loading is small.

The surface wind speed derived from modeling of the AirMSPI data is $6.7 \mathrm{~m} \mathrm{~s}^{-1}$. This compares well with a value of about $8 \mathrm{~m} \mathrm{~s}^{-1}$ obtained from daily Special Sensor Microwave/Imager (SSM/I) morning overpass data (http: //www.remss.com/ssmi/ssmibrowse.html) at the same location. The wind direction retrieved from AirMSPI has an azimuth of $26^{\circ}$ measured clockwise from the solar azimuth angle. An independent estimate of wind direction is obtained from visual analysis of the wave patterns observed in the AirMSPI imagery (see Fig. 8). The visually estimated normal to the oceanic wave fronts makes a clockwise angle of

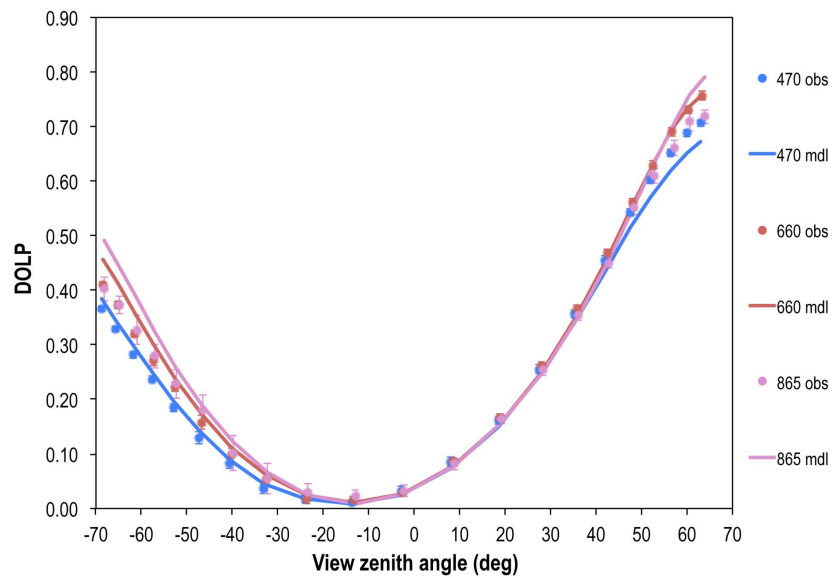

Fig. 11. Measured DOLP in the three polarimetric AirMSPI bands (circles) as a function of view zenith angle compared to results for the monomodal model with $0.06 \mu \mathrm{m}$ median particle radius (solid lines). Error bars represent the standard deviation in observed DOLP within the $100 \mathrm{~m} \times 100 \mathrm{~m}$ target area.

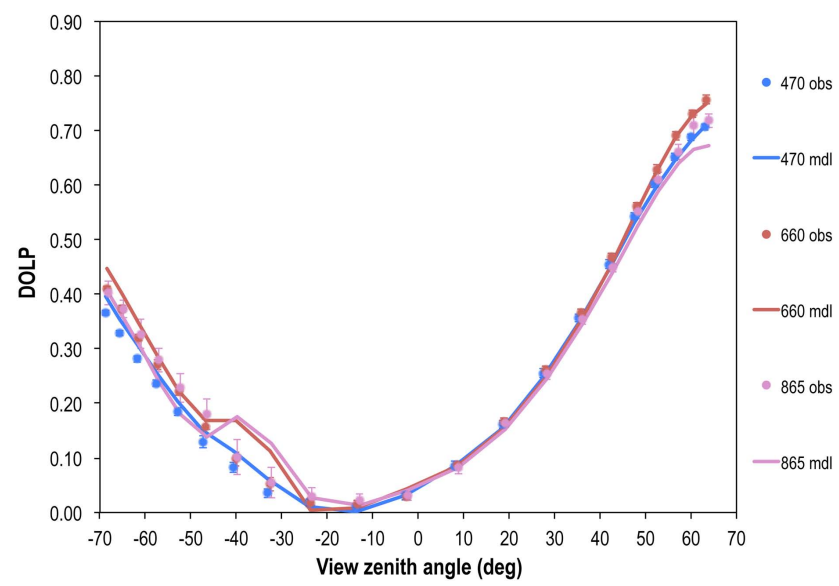

Fig. 12. Same as Fig. 11 but for the bimodal model with $40 \%$ of the $558 \mathrm{~nm}$ optical depth due to a fine mode with $0.03 \mu \mathrm{m}$ median particle radius and $60 \%$ due to a coarse mode with $1.00 \mu \mathrm{m}$ median particle radius. Relative to Fig. 11, fits are improved at the most oblique view zenith angles; however, the large particles in the model give rise to a bow between -30 and $-40^{\circ}$ view zenith angle that is not observed in the AirMSPI data.

about $24^{\circ}$ to the flight heading, which is $325^{\circ}$ from north. The average solar azimuth of $320^{\circ}$ during the AirMSPI image sequence therefore yields a wind direction of $29^{\circ}$ from solar meridian plane. The value derived using the Cox-Munk model to fit the angular sunglint pattern is in good agreement with this result.

\subsection{Hazy sky observations over land}

Several observational studies have demonstrated the benefits of combining multiangle intensity observations with polarimetry for constraining surface reflectance properties and 
Table 2. Surface parameters retrieved from fitting the AirMSPI data over the Fresno pond and residential area targets.

\begin{tabular}{lccccccccccc}
\hline & $a_{355}$ & $a_{380}$ & $a_{445}$ & $a_{470}$ & $a_{555}$ & $a_{660}$ & $a_{865}$ & $k$ & $b$ & $\zeta$ & $\sigma$ \\
\hline Pond & 0.000 & 0.018 & 0.030 & 0.027 & 0.030 & 0.033 & 0.041 & 0.259 & -0.205 & 0.352 & 0.122 \\
Res. area & 0.000 & 0.008 & 0.049 & 0.046 & 0.051 & 0.060 & 0.122 & 0.624 & -0.644 & 0.048 & 0.295 \\
\hline
\end{tabular}

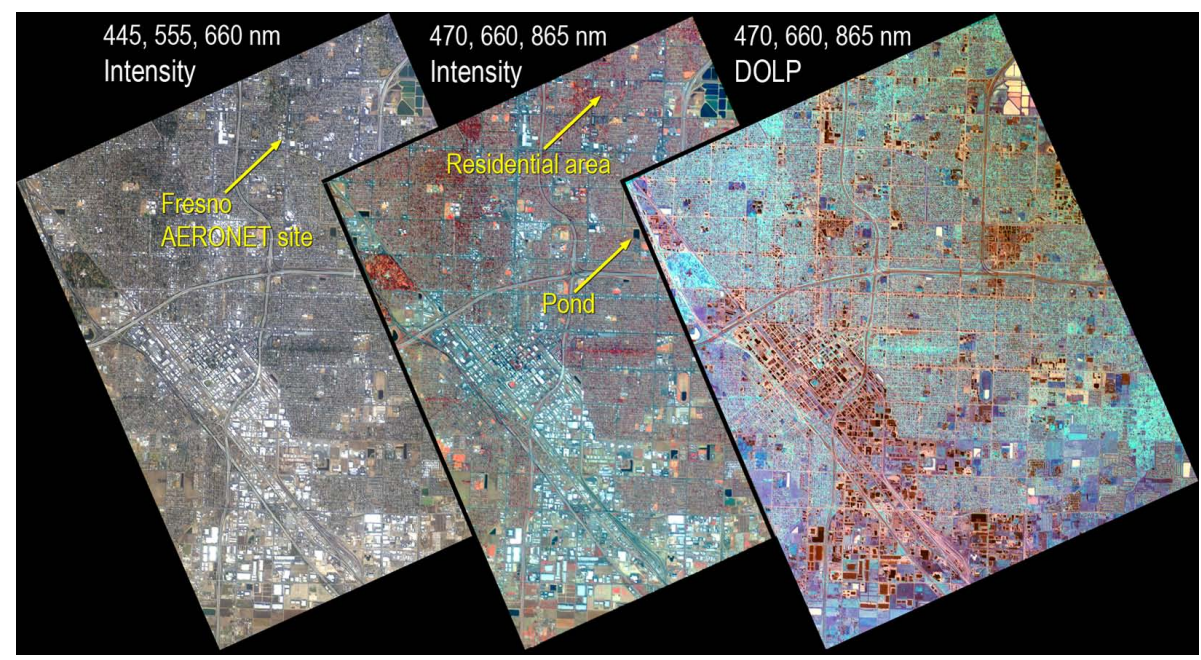

Fig. 13. AirMSPI nadir imagery of Fresno, CA, acquired on 6 January 2012. The left and middle images are intensity data using different spectral band combinations. The right image displays DOLP in the three polarimetric bands. The images have been contrast enhanced to highlight details. The locations of the Fresno AERONET site, the pond, and the residential area are indicated.

aerosol characteristics over land (e.g., Waquet et al., 2009; Tanré et al., 2011). Dubovik et al. (2011) developed a statistically optimized algorithm for retrieving aerosol properties and surface bidirectional reflectance parameters simultaneously, and successfully applied the methodology to POLDER observations over Africa. While a full aerosol retrieval is beyond the scope of this paper, a scene model was used to verify that the AirMSPI instrument is performing according to expectations, much as was done with the Pacific Ocean scene described above. AirMSPI flew over the Fresno, CA, AERONET site on 6 January 2012 (time of nadir view $=12: 23$ PST, 20:23 UTC), providing an opportunity for quantitative examination of the instrument's data. The atmosphere was quite hazy on this date (AERONET reported a mid-visible AOD, interpolated to $558 \mathrm{~nm}$ and the time of overpass, of 0.44). Figure 13 shows nadir images acquired during that overpass. The location of the Fresno AERONET site is marked. The calibration adjustments derived from the 19 July 2012 vicarious calibration against MISR were applied to the data. Due to the high spatial resolution of AirMSPI, adjacency effects ensure that diffuse transmission of surface-leaving radiation effectively averages over an area many times larger than the pixel size. The model used here assumes that the diffusely transmitted field results from a surface with the same bidirectional reflectance distribution function (BRDF) as that of the directly viewed surface, whereas a more rigorous retrieval algorithm would allow for spatial inhomogeneity in the surface BRDF. Data were extracted for two $100 \mathrm{~m} \times 100 \mathrm{~m}$ patches of ground: a pond located about $2.3 \mathrm{~km}$ to the southeast of the AERONET site, and a residential area $1.3 \mathrm{~km}$ to the northeast. These sites are marked in Fig. 13.

To model the AirMSPI data, the spectral AOD and aerosol size distribution derived from AERONET direct Sun and sky radiance data were used. The AERONET-derived size distribution is bimodal, with the fine mode accounting for $96 \%$ of the optical depth at $500 \mathrm{~nm}$, according to the spectral deconvolution algorithm used in AERONET processing (O'Neill et al., 2003). The size distribution and wavelength dependent particle refractive indices were based on AERONET Level 1.5 almucantar results (Dubovik et al., 2000). The volumetric size distribution reported by AERONET peaks at 0.26 and $2.94 \mu \mathrm{m}$ for the fine and coarse modes, respectively. The particle refractive index, interpolated to $558 \mathrm{~nm}$, is $1.445-0.005 i$. Absorption by ozone was handled in the same manner as for the ocean scene, described above. The data inversion permitted a small adjustment in AOD, and returned a $558 \mathrm{~nm}$ value of 0.39 , which is within the range of $0.37-$ 0.52 observed by AERONET within $\pm 1 \mathrm{~h}$ of the AirMSPI overpass.

The surface model is similar to that used by Diner et al. (2012) to model GroundMSPI data. The BRDF is taken to be the sum of a depolarizing modified Rahman-PintyVerstraete (mRPV) model (Martonchik et al., 1998) and a 


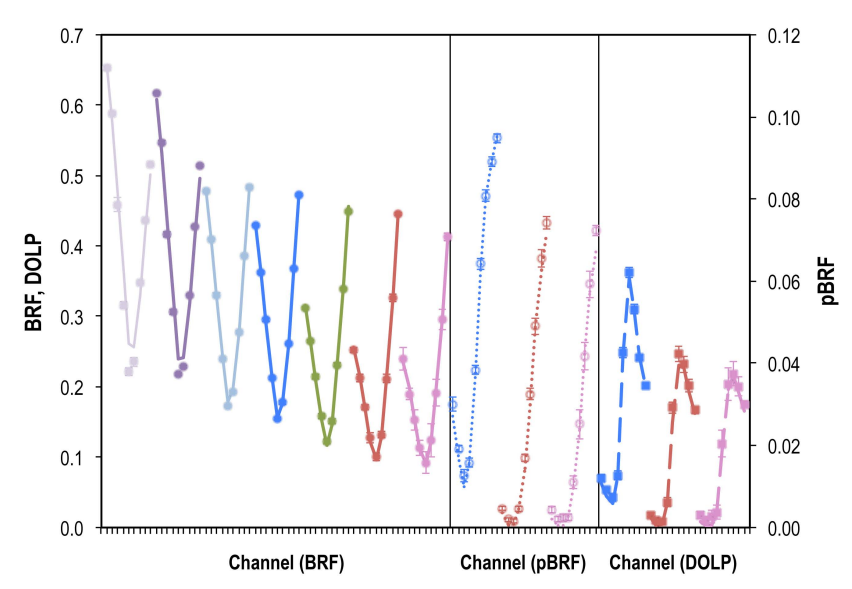

Fig. 14. Comparison of observed (circles) and modeled (lines) BRF in the $355,380,445,470,555,660$, and $865 \mathrm{~nm}$ bands (first seven curves from left to right), pBRF (obs as open circles, mdl as dotted lines) in the 470,660, and $865 \mathrm{~nm}$ bands (next three curves), and DOLP at the same wavelengths (obs as squares, mdl as dashed lines) (last three curves) at the nine view angles acquired over the Fresno pond target. Within each of the spectral curves, view zenith angles from left to right are 67.7, 60.9, 50.2, 31.8, 3.1, 27.9, 46.8, 58.1, and $65.3^{\circ}$. The left-hand $y$ axis is associated BRF and DOLP and the right-hand $y$ axis is associated with pBRF. Error bars correspond to standard deviations of the data within the $100 \mathrm{~m} \times 100 \mathrm{~m}$ target area.

polarizing term generated by an array of Fresnel-reflecting microfacets (Priest and Meier, 2002). The refractive index of the surface, $n_{\mathrm{r}, \text { surf }}$, is taken to be 1.5 (Waquet et al., 2009); however, in contrast to the ocean model, a wavelengthindependent factor, $\zeta$, multiplies the magnitude of the microfacet contribution to the BRDF to compensate for a possibly incorrect choice of $n_{\mathrm{r} \text {,surf }}$. An isotropic Gaussian distribution for the facet orientations is assumed, with RMS slope $\sigma$. The shadowing term of Tsang et al. (1985) was included. Keeping the parameters of the aerosol model fixed, the degrees of freedom of the scene model are the surface parameters $\zeta$, $\sigma$, the wavelength-dependent coefficients of the mRPV function, $a_{\lambda}$, and the wavelength-independent angular shape parameters $k$ (the exponent of a Minnaert-like function) and $b$ (which governs the dependence on scattering angle), for a total of 11 parameters. Values for these parameters were determined by fitting the model to the AirMSPI BRF and pBRF data simultaneously (90 measurements, corresponding to nine angles, seven bands for BRF and nine angles, three bands for polarized BRF).

Comparisons of modeled and measured BRF, pBRF, and DOLP are given in Figs. 14 (pond) and 15 (residential area) respectively. "Channel" refers to a particular combination of view zenith angle and spectral band. The fitted parameters are shown in Table 2. The negligible values of $a_{\lambda}$ at $355 \mathrm{~nm}$ indicate that the surface has negligible effect on the top-of-atmosphere measurements, likely owing to the intrinsically low surface reflectance and high atmospheric turbidity

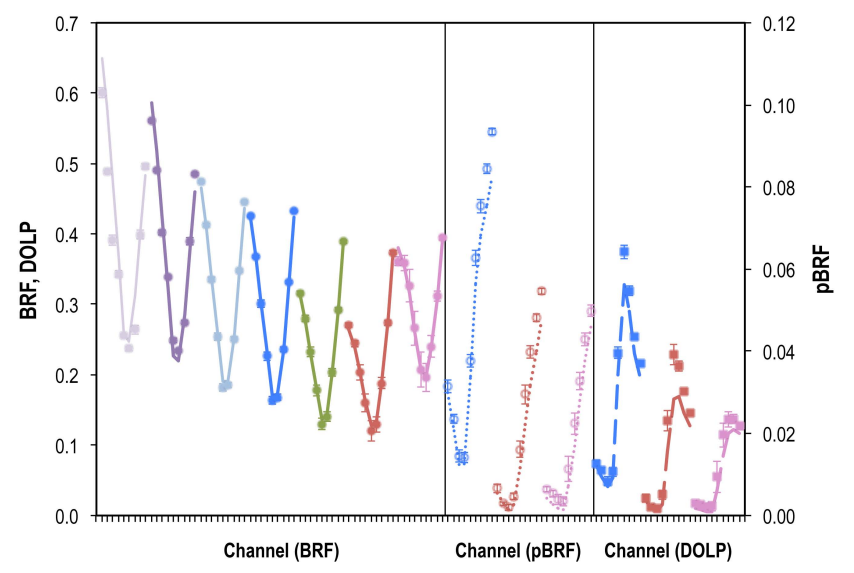

Fig. 15. Same as Fig. 14 except for the Fresno residential area target. Due to the slightly different position of this target within the instrument field of view, view zenith angles from left to right are $67.9,61.6,51.1,33.2,5.3,27.0,45.8,57.5$, and $64.8^{\circ}$ within each of the spectral curves.

(Rayleigh + aerosol optical depth $\cong 1.1)$ at this wavelength. For the residential area, $a_{\lambda}$ more than doubles at $865 \mathrm{~nm}$ compared with the mid-visible due to the presence of vegetation (trees and lawns). The higher negative value of $b$ for the vegetation is consistent with the expectation that areas with vertical structures (in this case, vegetation and buildings) cast shadows in the forward scattering direction and are brighter in backscatter. Although adjustments to the aerosol properties could conceivably improve the fits, the model for the most part reproduces the overall spectral and angular variations of BRF, pBRF, and DOLP observed by AirMSPI.

\subsection{Cloud observations}

The spatial context and coverage afforded by AirMSPI makes it possible to disentangle cloud effects from scattering by aerosols, account for variations in cloud polarization with scattering angle (e.g., Goloub et al., 1994; Alexandrov et al., 2012), and deal with both geometric parallax (apparent along-track shift in cloud position due to altitude above the surface) and true cloud motion. Techniques developed for MISR make automated retrieval of cloud-top heights $(\mathrm{CTH})$ and cloud motion vector (CMV) winds from multiangle stereo a mature technology (Moroney et al., 2002). Unlike infrared methods, stereo is insensitive to the atmospheric temperature profile and radiometric calibration making it particularly useful when inversions are present (Garay et al., 2008; Harshvardhan et al., 2009). The high quality and sensitivity of stereo imaging to boundary layer clouds ( $\mathrm{Wu}$ et al., 2009) enables geometric CTH to be used as a proxy for boundary layer height (Karlsson et al., 2010). Adaptation of MISR stereo retrieval software for use with AirMSPI is planned. The use of oblique view angle stereo has been shown to improve the detectability and height determination 


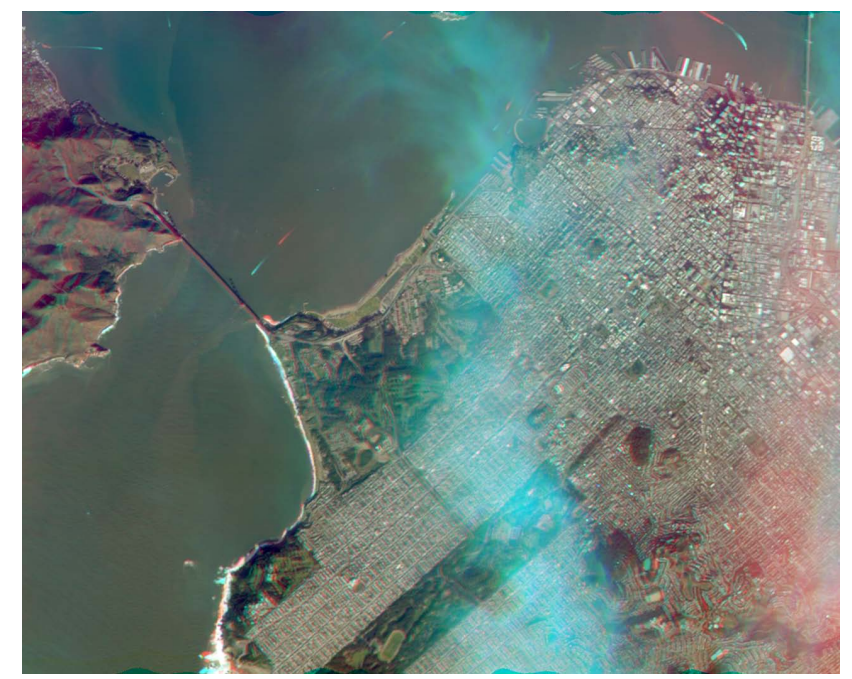

Fig. 16. Stereo anaglyph of San Francisco and a high-altitude cloud field generated using AirMSPI imagery at two view angles (approximately $4^{\circ}$ forward and $28^{\circ}$ aftward of nadir), acquired on 6 January $2012.660 \mathrm{~nm}$ data from the near-nadir view are displayed in red; 445 and $555 \mathrm{~nm}$ data from the aftward view are displayed in blue and green. The image is best viewed using red/cyan glasses with the red filter over the left eye to obtain a 3-D effect. The cloud parallax is too large for good image fusion, but surface topographic relief is apparent when the image is viewed with stereo glasses. North is toward the upper left. The motion of a boat approaching the Golden Gate Bridge is apparent due to the time lapse between the two images used to construct this anaglyph.

of thin cirrus (Prasad and Davies, 2012), and AirMSPI can capitalize on this technique as well.

To demonstrate the stereo information content of AirMSPI imagery, Fig. 16 is a stereo anaglyph of San Francisco generated using AirMSPI imagery acquired on 6 January 2012 between 01:08 and 01:09 PST (21:08 and 21:09 UTC) at two view angles (approximately $4^{\circ}$ forward and $28^{\circ}$ aftward of nadir). The near-nadir $660 \mathrm{~nm}$ intensities are displayed in red and the 445 and $555 \mathrm{~nm}$ intensities from the aftward view are displayed in blue and green. The image has been rotated $38^{\circ}$ counterclockwise to align the flight direction with the horizontal axis, and is best viewed using red/cyan glasses with the red filter over the left eye to get a 3-D effect. North is toward the upper left. The long, dark rectangular feature below center is Golden Gate Park, and the Golden Gate Bridge is visible to the left of center. Topographic relief is apparent within the city and in the terrain to the north of the Golden Gate Bridge. The largest stereo parallax (displacement) is observed over the clouds, which appear with a reddish tinge along the right-hand edge of the image, and in cyan in the aftward view. Estimates of the cloud parallax from this image pair and also between the 28 and $48^{\circ}$ aftward views places the cloud heights between 7 and $8 \mathrm{~km}$. National Weather Service (NWS) radiosonde soundings from Oakland, CA, at 00:00 UTC on 7 January 2012, obtained from the University

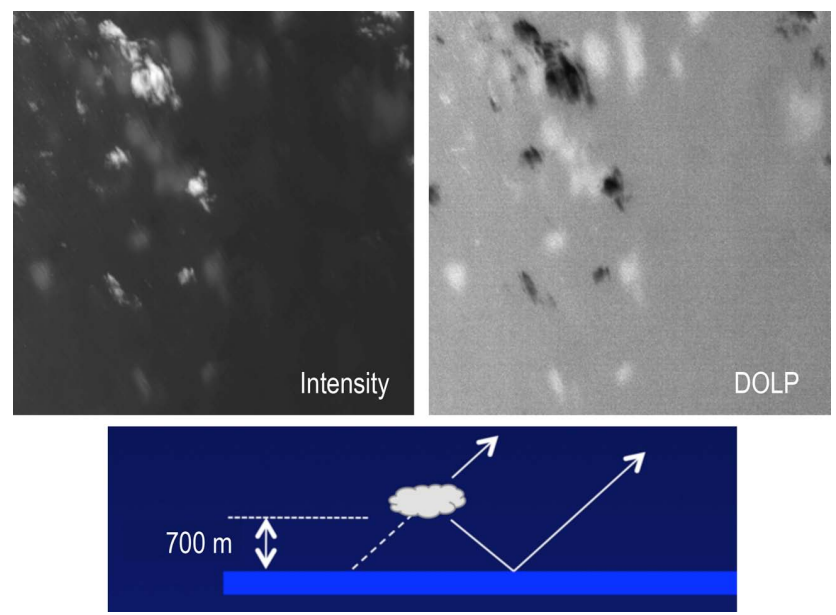

Fig. 17. Top left panel: $46^{\circ}$ forward view of $865 \mathrm{~nm}$ intensity showing clouds and cloud reflections in the ocean, acquired 7 October 2010. Top right panel: same view in DOLP. The clouds appear dark in polarization at this illumination and view geometry, but the cloud reflections in the water are highly polarized. Bottom panel: cartoon of cloud reflection in water and geometrically derived base height of $\sim 700 \mathrm{~m}$.

of Wyoming Department of Atmospheric Science website (http://weather.uwyo.edu/upperair/sounding.html), show the air temperature to be $-31.2^{\circ} \mathrm{C}$ at an altitude of $7.6 \mathrm{~km}$, consistent with these being primarily ice (cirrus) clouds, as evident from their wispy structure and optically thin appearance through which the surface can be seen.

Over ocean, off-nadir polarimetric imaging enhances the appearance of cloud reflections in the water. Since the source of illumination is the underside of the clouds, and cumulus clouds typically have flat bottoms and rounded tops, the separation between the cloud image and its reflection, or between cloud reflection images at different angles of view, enables estimation of cloud base height. Figure 17 shows AirMSPI images of clouds over the Pacific Ocean acquired on 7 October 2010 at $\sim 12: 25$ PDT (19:25 UTC). The left image is $865 \mathrm{~nm}$ intensity at a forward-looking view angle of $46^{\circ}$, showing cumulus clouds and the fainter reflections of the clouds in the water. At this view angle, clouds have low polarization and appear dark (right image), with DOLP as low as 0.03 . The cloud reflections in the water are the most polarized features, with DOLP as high as 0.80 . Polarization is likely enhanced due to the fact that the view direction is close to the Brewster angle for water $\left(53^{\circ}\right)$. When attempting to retrieve aerosol information from remotely sensed data over water, resolving such features may be necessary to ensure that the observations are uncontaminated either by clouds or their reflections. For studies of the clouds themselves, base height is valuable because it is a function of the thermodynamic structure and moisture content of the boundary layer (Wood, 2007), and determines the rate at which the cloud emits longwave radiation toward the surface. The cartoon in 


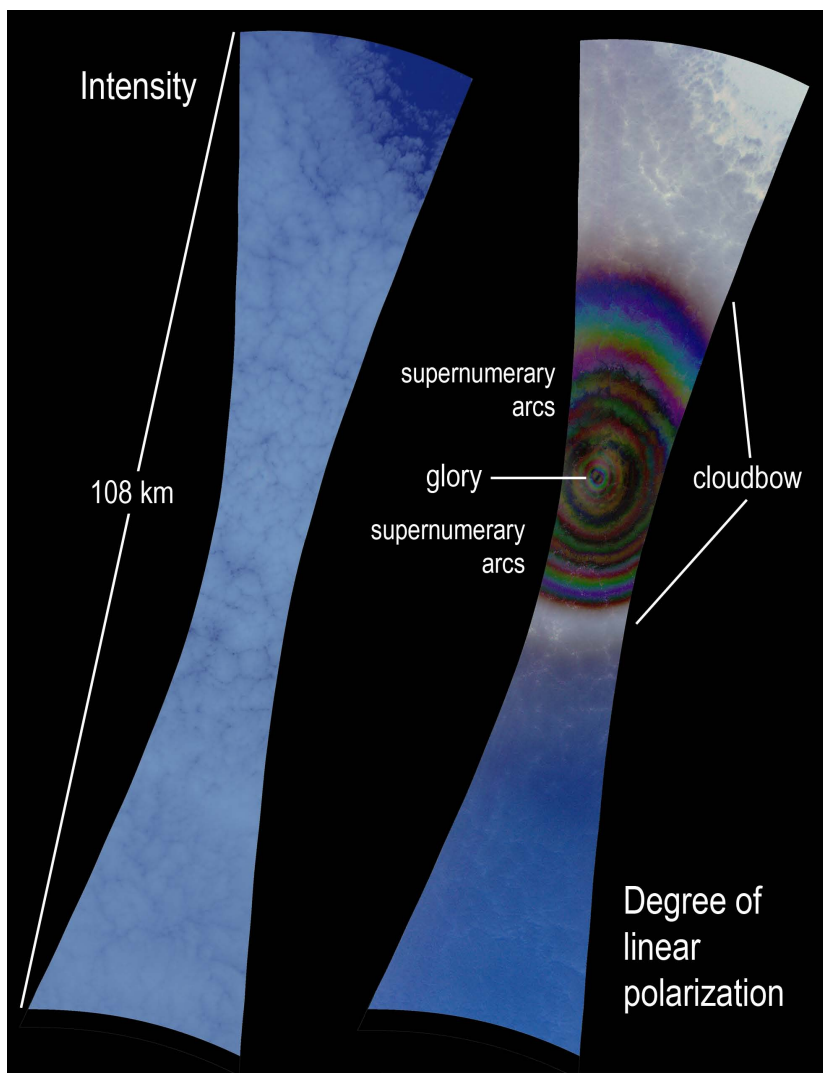

Fig. 18. AirMSPI stratocumulus cloud imagery at 470, 660, and $865 \mathrm{~nm}$ (left panel: intensity; right panel: DOLP) acquired in sweep mode on 31 August 2011 off the coast of California. In the DOLP image, the colored rings between the glory (near $180^{\circ}$ scattering angle) and primary cloudbow (near $143^{\circ}$ scattering angle) are supernumerary arcs - interference fringes resulting from the narrow spherical droplet size distribution. Multiple scattering washes out these features in the intensity image, but the glory is faintly visible.

Fig. 17 shows how the displacement between an off-nadir image of a cloud and its reflection gives an estimate of base height, assuming that the cloud is widest at this altitude. Measurements of the AirMSPI imagery imply an altitude of about $700 \mathrm{~m}$. NWS radiosonde soundings from the San Diego, CA, station at 00:00 UTC on 8 October 2010 show a steep increase in relative humidity centered at $610 \mathrm{~m}$ above sea level. The estimated height is also within the range of reported average cloud base heights of $430 \mathrm{~m}$ in the summer and $950 \mathrm{~m}$ in the winter for clouds off the California coast (Lin et al., 2009).

Analyses of data from the POLDER satellite instruments have shown that polarimetry at scattering angles corresponding to supernumerary cloudbows is sensitive to the mean and dispersion of cloud droplet size (Bréon and Goloub, 1998; Bréon and Doutriaux-Boucher, 2005). The primary cloudbow, supernumerary bows, and glory have also been observed in high-resolution AirMSPI imagery mapped to a $25 \mathrm{~m}$ grid (by comparison, POLDER resolution is about

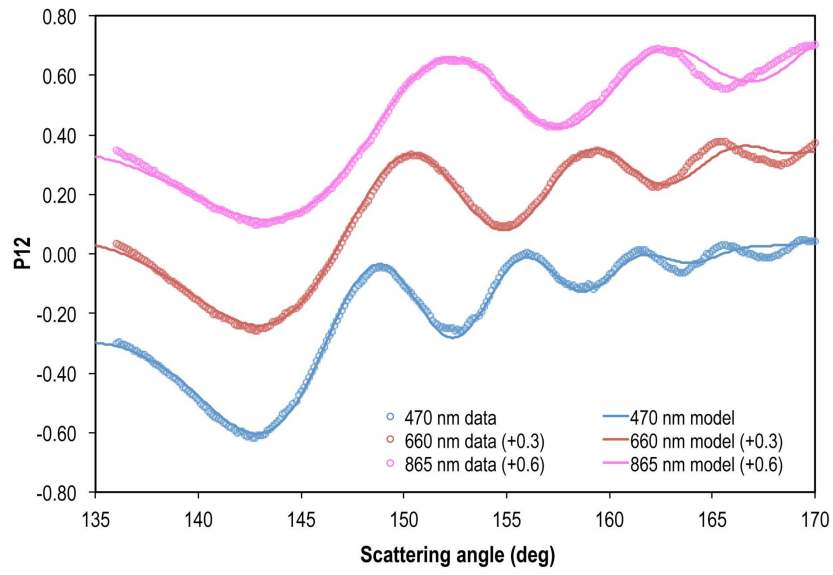

Fig. 19. Estimates of scattering phase matrix element $P_{12}$ derived from primary cloudbow and supernumerary bow data acquired by AirMSPI off the coast of Southern California on 31 August 2011 (open circles). Observations at the same scattering angle have been binned together in steps of $0.125^{\circ}$. Corrections for view and illumination geometry, Rayleigh transmittance and scattering, and ozone absorption have been applied to the data. The model results (solid lines) are derived following the methodology of Bréon and Goloub (1998). The results shown are for a droplet size distribution with an effective radius of $7.5 \mu \mathrm{m}$ and effective variance of 0.01 . The model takes into account the spectrally varying index of refraction of water. To make the plots more visible, the data and model results at $660 \mathrm{~nm}$ have been offset upwards by 0.3 , and the results at $865 \mathrm{~nm}$ have been offset upwards by 0.6 .

$6 \mathrm{~km})$. Figure 18 shows AirMSPI intensity and DOLP imagery of marine stratocumulus clouds off the coast of Southern California, acquired on 31 August 2011 at 12:51 PDT (19:51 UTC). The data were obtained in the instrument's sweep mode, and the bowtie shape results from the increase in swath width with increasing view angle, which ranges between $\pm 65.5^{\circ}$ from nadir. The images are 470,660 , and $865 \mathrm{~nm}$ composites. The glory appears near scattering angle, $\Omega$, of $180^{\circ}$ (Sun directly behind the instrument), and $\Omega$ decreases systematically away from this point. In polarized light, the clouds appear dark (low DOLP) at $\Omega<140^{\circ}$, and DOLP increases significantly within the spectrally neutral cloudbow near $\Omega \sim 143^{\circ}$. The DOLP image shows supernumerary arcs at larger scattering angles. These colorful features are due to spectrally distinct fringes resulting from interference of light waves within the spherical cloud droplets. Quantitative analysis of the supernumerary bow data is shown in Fig. 19, following the single-scattering analysis method of Bréon and Goloub (1998). To facilitate the application of single-scattering theory, only measurements near the principal plane were used, in which case $U$ is close to zero, even in the presence of multiple scattering. The $Q$ observations at wavelength $\lambda$ were analyzed according to the following equation: 


$$
\begin{aligned}
& Q_{\mathrm{obs}, \lambda}=\frac{\mu_{0} E_{0 \lambda}}{4 \pi\left(\mu+\mu_{0}\right)}\left[P_{12, \lambda}(\Omega) e^{-\tau_{\mathrm{R}, \lambda}\left(\frac{1}{\mu}+\frac{1}{\mu_{0}}\right)}\right. \\
& \left.+P_{12, \text { Ray }}(\Omega)\left(1-e^{-\tau_{\mathrm{R}, \lambda}\left(\frac{1}{\mu}+\frac{1}{\mu_{0}}\right)}\right)\right] e^{-\tau_{\mathrm{ozone}, \lambda}\left(\frac{0.2}{\mu}+\frac{1}{\mu_{0}}\right)},
\end{aligned}
$$

where $E_{0 \lambda}$ is the solar spectral irradiance; $\mu$ and $\mu_{0}$ are cosines of the view and solar zenith angles, respectively; $\tau_{\mathrm{R}, \lambda}$ is the Rayleigh optical depth above the cloud top, assumed to be at $1 \mathrm{~km}$ altitude (a typical height for marine stratocumulus clouds); and $\tau_{\text {ozone }, \lambda}$ is a climatological estimate of the ozone optical depth, with the factor of 0.2 in the exponent resulting from the assumption that only $20 \%$ of the ozone columnintegrated optical depth is situated below the aircraft altitude. As in Bréon and Goloub (1998), the cloud is assumed to be sufficiently optically thick such that terms involving transmission through the cloud may be neglected. $P_{12 \text {, Ray }}$ denotes the first row, second column element of the Rayleigh scattering phase matrix, equal to $-0.75 \sin ^{2} \Omega$, and $P_{12, \lambda}$ signifies the corresponding element for the other scatterers in the scene. This term is established primarily by single scattering from the main cloud deck but implicitly includes factors such as multiple scattering, aerosol, and cirrus effects (Alexandrov et al., 2012). For each observation of $Q$ included in the analysis, Eq. (1) is inverted to obtain $P_{12, \lambda}$, which is then binned by scattering angle in steps of $0.125^{\circ}$. Results derived from the observations at 470, 660, and $865 \mathrm{~nm}$ for the scattering range 135 to $170^{\circ}$ are shown in Fig. 19 as the open circles. The primary cloudbow appears at $\Omega \sim 143^{\circ}$, and the supernumerary arcs at each wavelength appear with progressively diminishing amplitude as scattering angle increases. Note that the number of fringes increases as wavelength decreases, as expected for an interference phenomenon in which there are more blue wavelengths than red wavelengths per given drop diameter.

The solid lines in Fig. 19 are obtained by fitting the values of $P_{12, \lambda}$ derived from the observations to the following model:

$P_{12, \lambda}=a_{\lambda} P_{12, \mathrm{cld}, \lambda}+b_{\lambda} \Omega+c_{\lambda}$,

where $P_{12, \text { cld }, \lambda}$ is the first row, second column element of the single-scattering phase matrix for the cloud deck, established using Mie theory for a narrow distribution of spherical droplet sizes. The spectrally variable $a, b, c$ coefficients are determined empirically by least-squares fitting. The form of Eq. (2) was introduced by Bréon and Goloub (1998) as a simple way of accounting for unmodeled scene effects. An alternative fitting approach, introduced by Alexandrov et al. (2012), eliminates the Rayleigh correction procedure and uses $\cos ^{2} \Omega$ instead of $\Omega$ in the second term on the right hand side of Eq. (2). Both methods yielded similar results. A size distribution in which the number of droplets between radius $r$ and $r+\mathrm{d} r$ is proportional to $\left(r / r_{\text {eff }}\right)^{v_{\text {eff }}^{-1}-3} \exp \left(-r / r_{\text {eff }} v_{\text {eff }}\right)$ was used (Hansen, 1971; Bréon and Goloub, 1998; Bréon and Doutriaux-Boucher, 2005), where $r_{\text {eff }}$ is the effective radius and $v_{\text {eff }}$ is the effective variance. A narrow cloud droplet size distribution with $r_{\text {eff }}=7.5 \mu \mathrm{m}$ and $v_{\text {eff }}=0.01$ generated the model results shown in Fig. 19. The spectral dependence of the refractive index of water needs to be taken into account, as noted by Bréon and Doutriaux-Boucher (2005). A sixth-degree polynomial fit to the data of Daimon and Masumura (2007) for distilled water at a temperature of $19^{\circ} \mathrm{C}$ was used to derive the real part of the index of refraction of $1.3385(470 \mathrm{~nm}), 1.3315(660 \mathrm{~nm})$, and $1.3276(865 \mathrm{~nm})$ This temperature is consistent with the average value over the lowest $1 \mathrm{~km}$ of the atmosphere $\left(\sim 21^{\circ} \mathrm{C}\right)$ determined from San Diego radiosonde data at 12:00 UTC on 31 August 2011 and 00:00 UTC on 1 September 2011. Small changes on the order of 0.001 in the index of refraction cause noticeable shifts in the location of the primary cloudbow and supernumerary arcs with respect to scattering angle, resulting in poorer fits. Improved fits could likely be obtained using more rigorous analysis and including aerosols and multiple scattering effects.

\section{Conclusions}

AirMSPI has been flying aboard NASA's ER-2 high-altitude aircraft since October 2010. At the heart of the instrument is an eight-band spectropolarimetric camera that acquires multiangle imagery through a combination of aircraft motion and actuation on a single-axis gimbal. AirMSPI employs a dual PEM-based polarimetric imaging technique to determine degree and angle of linear polarization (DOLP and AOLP) on a pixel-by-pixel basis as relative measurements, independent of instrument absolute radiometric calibration. This methodology was first introduced through theoretical formulation and bench testing (Diner et al., 2007), and has subsequently matured into progressively more sophisticated imaging instruments, beginning with the monochromatic LabMSPI (Diner et al., 2010), the UV/VNIR groundbased camera GroundMSPI (Diner et al., 2012), and most recently, the UV/VNIR airborne sensor, AirMSPI. The MSPI team is currently developing a second-generation instrument, AirMSPI-2, which extends the spectral range into the SWIR. Since the AirMSPI optical coatings perform well over the entire UV-SWIR spectral range (see Sect. 2.1), AirMSPI-2 uses the same coating design for its mirrors.

Development and demonstration of the technology to acquire accurate polarimetric imagery represent major steps toward realization of the type of instrument envisioned to be part of the core payload of NASA's Aerosol-CloudEcosystem (ACE) mission, currently in the formulation stages. Using example data acquisitions of clear, hazy, and cloudy skies over the Pacific Ocean and California, we have interpreted the AirMSPI imagery through the use of geophysical scene models and radiative transfer theory. Sensitivities to particle microphysical parameters such as aerosol and 
cloud droplet size, morphological parameters such as cloudtop and cloud-base height, and ocean surface wind speed and direction have been demonstrated through visualizations and analyses. This type of data evaluation is an essential precursor to implementation of geophysical retrieval algorithms, which are currently undergoing development.

Recent efforts have focused on improvements and upgrades to the equipment and procedures used for radiometric, polarimetric, and spectral calibration of the AirMSPI camera. AirMSPI L1B2 data products will be publicly released through the NASA Langley Atmospheric Sciences Data Center, beginning in mid-2013. We look forward to productive utilization of this new remote sensing resource by the scientific community.

Acknowledgements. The authors thank the entire AirMSPI engineering team for their efforts. This research is being carried out at the Jet Propulsion Laboratory, California Institute of Technology under contract with NASA, and at the University of Arizona College of Optical Sciences, the University of Texas Center for Space Research, and the University of California Joint Institute for Regional Earth System Science and Engineering (JIFRESSE) under subcontract with JPL. Funding from the NASA Instrument Incubator Program, Airborne Instrument Technology Transition Program, and Earth Science Research Program is gratefully acknowledged. We thank Brent Holben and Carol Bruegge for their efforts in establishing and maintaining the UCSB and Fresno AERONET sites.

Edited by: O. Dubovik

\section{References}

ACE Science Working Group: Aerosol, Cloud and Ecosystems (ACE) Proposed Satellite Mission Study Report, available at: http://dsm.gsfc.nasa.gov/ace/library.html (last access: 11 February 2013), 2010.

Alexandrov, M. D., Cairns, B., Emde, C., Ackerman, A. S., and van Diedenhoven, B.: Accuracy assessments of cloud droplet size retrievals from polarized reflectance measurements by the research scanning polarimeter, Remote Sens. Environ., 125, 92111, 2012.

Bréon, F.-M. and Doutriaux-Boucher, M.: A comparison of cloud droplet radii measured from space, IEEE T. Geosci. Remote, 43, 1796-1805, 2005.

Bréon, F.-M. and Goloub, P.: Cloud droplet effective radius from spaceborne polarization measurements, Geophys. Res. Lett., 25, 1879-1882, 1998.

Bréon, F.-M. and Henriot, N.: Spaceborne observations of ocean glint reflectance and modeling of wave slope distributions, J. Geophys. Res., 111, C06005, doi:10.1029/2005JC003343, 2006.

Bruegge, C. J., Chrien, N. L., Diner, D. J., Kahn, R. A., and Martonchik, J. V.: MISR radiometric uncertainty analyses and their utilization within geophysical retrievals, Metrologia, 35, 571579, 1998.
Cairns, B., Russell, E. E., LaVeigne, J. D., and Tennant, P. M. W.: Research scanning polarimeter and airborne usage for remote sensing of aerosols, Proc. SPIE, 5158, 33-44, 2003.

CCSP - Climate Change Science Program: Atmospheric Aerosol Properties and Climate Impacts, A Report by the US CCSP and the Subcommittee on Global Change Research, edited by: Chin, M., Kahn, R. A., and Schwartz, S. E., National Aeronautics and Space Administration, Washington, D.C., USA, 128 pp., 2009.

Chowdhary, J., Cairns, B., Mishchenko, M., and Travis, L.: Retrieval of aerosol properties over the ocean using multispectral and multiangle photopolarimetric measurements from the Research Scanning Polarimeter, Geophys. Res. Lett., 28, 243-246, 2001.

Chowdhary, J., Cairns, B., and Travis, L. D.: Case studies of aerosol retrievals over the ocean from multiangle, multispectral photopolarimetric remote sensing data, J. Atmos. Sci., 59, 383-397, 2002.

Chowdhary, J., Cairns, B., and Travis, L. D.: Contribution of waterleaving radiances to multiangle, multispectral polarimetric observations over the open ocean: bio-optical model results for case 1 waters, Appl. Optics, 45, 5542-5567, 2006.

Chowdhary, J., Cairns, B., Waquet, F., Knobelspiesse, K., Ottaviani, M., Redemann, J., Travis, L., and Mishchenko, M.: Sensitivity of multiangle, multispectral polarimetric remote sensing over open oceans to water-leaving radiance: analyses of RSP data acquired during the MILAGRO campaign, Remote Sens. Environ., 118, 284-308, 2012.

Cox, C. and Munk, W.: Slopes of the sea surface deduced from photographs of sun glitter, Bull. Scripps Inst. Oceanogr., 6, 401-488, 1956.

Daimon, M. and Masumura, A.: Measurement of the refractive index of distilled water from the near-infrared region to the ultraviolet region, Appl. Optics, 46, 3811-3820, 2007.

Diner, D. J., Beckert, J. C., Reilly, T. H., Bruegge, C. J., Conel, J. E., Kahn, R. A., Martonchik, J. V., Ackerman, T. P., Davies, R., Gerstl, S. A. W., Gordon, H. R., Muller, J.-P., Myneni, R. B., Sellers, P. J., Pinty, B., and Verstraete, M.: Multi-angle Imaging SpectroRadiometer (MISR) instrument description and experiment overview, IEEE T. Geosci. Remote, 36, 1072-1087, 1998a.

Diner, D. J., Barge, L. M., Bruegge, C. J., Chrien, T. G., Conel, J. E., Eastwood, M. L., Garcia, J. D., Hernandez, M. A., Kurzweil, C. G., Ledeboer, W. C., Pignatano, N. D., Sarture, C. M., and Smith, B. G.: The Airborne Multi-angle Imaging SpectroRadiometer (AirMISR): Instrument description and first results, IEEE T. Geosci. Remote, 36, 1339-1349, 1998 b.

Diner, D. J., Davis, A., Hancock, B., Gutt, G., Chipman, R. A., and Cairns, B.: Dual photoelastic modulator-based polarimetric imaging concept for aerosol remote sensing, Appl. Optics, 46, 8428-8445, 2007.

Diner, D. J., Davis, A., Hancock, B., Geier, S., Rheingans, B., Jovanovic, V., Bull, M., Rider, D. M., Chipman, R. A., Mahler, A., and McClain, S. C.: First results from a dual photoelastic modulator-based polarimetric camera, Appl. Optics, 49, 2929 2946, 2010.

Diner, D. J., Pingree, P. J., and Chipman, R. A.: Novel airborne imaging polarimeter undergoes flight testing, SPIE Newsroom, 14 November 2011, available at: http://spie.org/x83155.xml?pf= true $\backslash \&$ ArticleID=x83155 (last access: 11 February 2013), 2011. 
Diner, D. J., Xu, F., Martonchik, J. V., Rheingans, B. E., Geier, S., Jovanovic, V. M., Davis, A., Chipman, R. A., and McClain, S. C.: Exploration of a polarized surface bidirectional reflectance model using the Ground-based Multiangle SpectroPolarimetric Imager, Atmosphere, 3, 591-619, 2012.

Dubovik, O., Smirnov, A., Holben, B. N., King, M. D., Kaufman, Y. J., Eck, T. F., and Slutsker, I.: Accuracy assessment of aerosol optical properties retrieval from AERONET sun and sky radiance measurements, J. Geophys. Res., 105, 9791-9806, 2000.

Dubovik, O., Herman, M., Holdak, A., Lapyonok, T., Tanré, D., Deuzé, J. L., Ducos, F., Sinyuk, A., and Lopatin, A.: Statistically optimized inversion algorithm for enhanced retrieval of aerosol properties from spectral multi-angle polarimetric satellite observations, Atmos. Meas. Tech., 4, 975-1018, doi:10.5194/amt-4975-2011, 2011.

Garay, M. J., de Szoeke, S. P., and Moroney, C. M.: Comparison of marine stratocumulus cloud top heights in the Southeastern Pacific retrieved from satellites with coincident ship-based observations, J. Geophys. Res., 113, D18204, doi:10.1029/2008JD009975, 2008.

Goloub, P., Deuzé, J. L., Herman, M., and Fouquart, Y.: Analysis of the POLDER polarization measurements performed over cloud covers, IEEE T. Geosci. Remote, 32, 78-88, 1994.

Hansen, J. E.: Multiple scattering of polarized light in planetary atmospheres, Part II. Sunlight reflected by terrestrial water clouds, J. Atmos. Sci., 28, 1400-1426, 1971.

Harshvardhan, Zhao, G., Di Girolamo, L., and Green, R. N.: Satellite-observed location of stratocumulus cloud-top heights in the presence of strong inversions, IEEE T. Geosci. Remote, 47, 1421-1428, 2009.

Hasekamp, O. P. and Landgraf, J.: Retrieval of aerosol properties over land surfaces: capabilities of multiple-viewing-angle intensity and polarization measurements, Appl. Optics, 46, 33323344, 2007.

Hasekamp, O. P., Litvinov, P., and Butz, A.: Aerosol properties over the ocean from PARASOL multiangle photopolarimetric measurements, J. Geophys. Res., 116, D14204, doi:10.1029/2010JD015469, 2011.

Holben, B. N., Eck, T. F., Slutsker, I., Tanré, D., Buis, J. P., Setzer, A., Vermote, E., Reagan, J. A., Kaufman, Y. J., Nakajima, T., Lavenu, F., Jankowiak, I., and Smirnov, A.: AERONET - a federated instrument network and data archive for aerosol characterization, Remote Sens. Environ., 66, 1-16, 1998.

Jovanovic, V., Ledeboer, B., Smyth, M., and Zong, J.: Georectification of the Airborne Multiangle Imaging SpectroRadiometer, available at: http://trs-new.jpl.nasa.gov/dspace/handle/2014/ 13195, last access: 11 February 2013, ISPRS Workshop on High Resolution Mapping from Space, Hannover, Germany, 2001.

Jovanovic, V. M., Bull, M. A., Smyth, M. M., and Zong, J.: MISR in-flight camera geometric model calibration and georectification performance, IEEE T. Geosci. Remote, 40, 1512-1519, 2002.

Jovanovic, V. M., Bull, M., Diner, D. J., Geier, S., and Rheingans, B.: Automated data production for a novel Airborne Multiangle SpectroPolarimetric Imager (AirMSPI), Int. Arch. Photogramm. Remote Sens. Spatial Inf. Sci., XXXIX-B1, 33-38, doi:10.5194/isprsarchives-XXXIX-B1-33-2012, 2012.
Kahn, R. A., Gaitley, B. J., Garay, M. J., Diner, D. J., Eck, T. F., Smirnov, A., and Holben, B. N.: Multiangle Imaging SpectroRadiometer global aerosol product assessment by comparison with the Aerosol Robotic Network, J. Geophys. Res., 115, D23209, doi:10.1029/2010JD014601, 2010.

Karlsson, J., Svensson, G., Cardoso, S., Teixeira, J., and Paradise, S.: Subtropical cloud-regime transitions: boundary layer depth and cloud-top height evolution in models and observations, J. Appl. Meteorol. Clim., 49, 1845-1858, 2010.

Kawata, Y.: Circular polarization of sunlight reflected by planetary atmospheres, Icarus, 33, 217-232, 1978.

Koelemeijer, R. B. A., de Haan, J. F., and Stammes, P.: A database of spectral surface reflectivity in the range $335-772 \mathrm{~nm}$ derived from 5.5 years of GOME observations, J. Geophys. Res., 108, 4070, doi:10.1029/2002JD002429, 2003.

Kokhanovsky, A. A., Deuzé, J. L., Diner, D. J., Dubovik, O., Ducos, F., Emde, C., Garay, M. J., Grainger, R. G., Heckel, A., Herman, M., Katsev, I. L., Keller, J., Levy, R., North, P. R. J., Prikhach, A. S., Rozanov, V. V., Sayer, A. M., Ota, Y., Tanré, D., Thomas, G. E., and Zege, E. P.: The inter-comparison of major satellite aerosol retrieval algorithms using simulated intensity and polarization characteristics of reflected light, Atmos. Meas. Tech., 3, 909-932, doi:10.5194/amt-3-909-2010, 2010.

Lebsock, M. D., L'Ecuyer, T., and Stephens, G. L.: Information content of near-infrared spaceborne multiangular polarization measurements for aerosol retrievals, J. Geophys. Res., 112, D14206, doi:10.1029/2007JD008535, 2007.

Lin, W., Zhang, M., and Loeb, N. G.: Seasonal variation of the physical properties of marine boundary layer clouds off the California coast, J. Climate, 22, 2624-2638, 2009.

Lohmann, U. and Feichter, J.: Global indirect aerosol effects: a review, Atmos. Chem. Phys., 5, 715-737, doi:10.5194/acp-5-7152005, 2005.

Mahler, A., Raouf, N. A., Smith, P. K., McClain, S. C., and Chipman, R. A.: Minimizing instrumental polarization in the Multiangle SpectroPolarimetric Imager (MSPI) using diattenuation balancing between the three mirror coatings, Proc. SPIE, 7013, 701355, doi:10.1117/12.791941, 2008.

Mahler, A., Diner, D. J., and Chipman, R. A.: Analysis of static and time-varying polarization errors in the multiangle spectropolarimetric imager, Appl. Optics, 50, 2080-2087, 2011a.

Mahler, A., McClain, S., and Chipman, R.: Achromatic athermalized retarder fabrication, Appl. Optics, 50, 755-765, $2011 \mathrm{~b}$.

Martonchik, J. V., Diner, D. J., Pinty, B., Verstraete, M. M., Myneni, R. B., Knyazikhin, Y., and Gordon, H. R.: Determination of land and ocean reflective, radiative, and biophysical properties using multiangle imaging, IEEE T. Geosci. Remote, 36, 1266-1281, 1998.

Mishchenko, M. I. and Travis, L. D.: Satellite retrieval of aerosol properties over the ocean using polarization as well as intensity of reflected sunlight, J. Geophys. Res., 102, 16989-17014, 1997.

Moroney, C., Davies, R., and Muller, J.-P.: Operational retrieval of cloud-top heights using MISR data, IEEE T. Geosci. Remote, 40, 1532-1540, 2002.

NRC - National Research Council: Committee on Earth Science and Applications from Space: Earth Science and Applications from Space: National Imperatives for the Next Decade and Beyond, The National Academies Press, Washington, D.C., 437 pp., 2007. 
O’Neill, N. T., Eck, T. F., Smirnov, A., Holben, B. N., and Thulasiraman, S.: Spectral discrimination of coarse and fine mode optical depth, J. Geophys. Res., 108, 4559-4573, 2003.

Plass, G. N., Kattawar, G. W., and Hitzfelder, S. J.: Multiple scattered radiation emerging from Rayleigh and continental haze layers - 2. Ellipticity and direction of polarization, Appl. Optics, 15, 1003-1011, 1976.

Prasad, A. A. and Davies, R.: Detecting tropical thin cirrus using Multiangle Imaging SpectroRadiometer's oblique cameras and modeled outgoing longwave radiation, J. Geophys. Res., 117, D06208, doi:10.1029/2011JD016798, 2012.

Priest, R. G. and Meier, S. R.: Polarimetric microfacet scattering theory with applications to absorptive and reflective surfaces, Opt. Eng., 41, 988-993, 2002.

Randall, D. A., Wood, R. A., Bony, S., Colman, R., Fichefet, T., Fyfe, J., Kattsov, V., Pitman, A., Shukla, J., Noda, A., Srinivasan, J., Stouffer, R. J., Sumi, A., and Taylor, K. E.: Climate models and their evaluation, In Climate change 2007: The Physical Science Basis, Contribution of Working Group I to the Fourth Assessment Report of the Intergovernmental Panel on Climate Change, edited by: Solomon, S., Qin, D., Manning, M., Chen, Z., Marquis, M., Averyt, K. B., Tignor, M., and Miller, H. L., Cambridge University Press, Cambridge, UK and New York, NY, USA, 2007.

Tanré, D., Bréon, F. M., Deuzé, J. L., Dubovik, O., Ducos, F., François, P., Goloub, P., Herman, M., Lifermann, A., and Waquet, F.: Remote sensing of aerosols by using polarized, directional and spectral measurements within the A-Train: the PARASOL mission, Atmos. Meas. Tech., 4, 1383-1395, doi:10.5194/amt-4-1383-2011, 2011.
Torres, O., Herman, J. R., Bhartia, P. K., and Sinyuk, A.: Aerosol properties from EP-TOMS near UV observations, Adv. Space Res., 29, 1771-1780, 2002.

Tsang, L., Kong, J. A., and Shin, R.: Theory of Microwave Remote Sensing, Chapter 2, Wiley-Interscience, New York, 93-96, 1985.

Waquet, F., Cairns, B., Knobelspiesse, K., Chowdhary, J., Travis, L. D., Schmid, B., and Mishchenko, M. I.: Polarimetric remote sensing of aerosols over land, J. Geophys. Res., 114, D01206, doi:10.1029/2008JD010619, 2009.

Wood, R.: Cancellation of aerosol indirect effects in marine stratocumulus through cloud thinning, J. Atmos. Sci., 64, 26572669, 2007.

Wu, D. L., Ackerman, S. A., Davies, R., Diner, D. J., Garay, M. J., Kahn, B. H., Maddux, B. C., Moroney, C. M., Stephens, G. L., Veefkind, J. P., and Vaughan, D. M.: Vertical distributions and relationships of cloud occurrence frequency as observed by MISR, AIRS, MODIS, OMI, CALIOP, and CloudSat, Geophys. Res. Lett., 36, L09821, doi:10.1029/2009GL037464, 2009.

Xu, F., Davis, A. B., West, R. A., Martonchik, J. V., and Diner, D. J.: Markov chain formalism for vector radiative transfer in a planeparallel atmosphere overlying a polarizing surface, Opt. Lett., 36, 2083, doi:10.1364/OL.36.002083, 2011.

Zhai, P.-W., Hu, Y., Chowdhary, J., Trepte, C. R., Lucker, P. L., and Josset, D. B.: A vector radiative transfer model for coupled atmosphere and ocean systems with a rough interface, J. Quant. Spectrosc. Ra., 111, 1025-1040, 2010. 